\title{
Stability and Change of Perceived Characteristics of Major Life Events
}

\author{
Peter Haehner ${ }^{1}$, Sarah Kritzler ${ }^{1}$, Ina Fassbender ${ }^{2}$ and Maike Luhmann ${ }^{1}$ \\ ${ }^{1}$ Department of Psychology, Ruhr University Bochum \\ ${ }^{2}$ Department of Education Studies and Psychology, University of Siegen
}

This paper has been accepted for publication at Journal of Personality and Social Psychology, May 24, 2021. (C) 2021, American Psychological Association. This paper is not the copy of record and may not exactly replicate the final, authoritative version of the article. Please do not copy or cite without authors' permission. The final article will be available, upon publication, via its DOI: 10.1037/pspp0000394 


\begin{abstract}
Author Note
Peter Haehner (iD) https://orcid.org/0000-0002-3896-6172

Sarah Kritzler (D) https://orcid.org/0000-0002-9682-1502

Ina Fassbender (iD) https://orcid.org/0000-0003-0423-6259

Maike Luhmann (iD https://orcid.org/0000-0001-6211-9304
\end{abstract}

The study design was preregistered at https://osf.io/kvf5g/. The preregistration of the present analyses, the data, and R scripts can be retrieved from https://osf.io/urqdw/?view_only=e97f3517abe8466fb5a1a9dcb430f908. We have no known conflict of interest to disclose. Data collection was funded by Pathways to Character Project (sponsored by the John Templeton Foundation and the Arizona State University Foundation), Grant 60699 to Maike Luhmann.

Correspondence concerning this article should be addressed to Peter Haehner, Department of Psychology, Ruhr University Bochum, Universitaetsstr. 150, 44780 Bochum, Germany. Email: peter.haehner@rub.de

We would like to thank Charles Driver for sharing his expertise on continuous time models with us in the revision of this manuscript. We would also like to thank him and the anonymous reviewers for their detailed and constructive reviews. 


\begin{abstract}
The occurrence of major life events is associated with changes in well-being and personality. To better understand these effects, it is important to consider how individuals perceive major life events. Although theories such as appraisal theory and affective adaptation theory suggest that event perceptions change over time and that these changes are relevant for personality and well-being, stability and change of perceived event characteristics have not been systematically examined. This paper aims to fill this gap using data from a longitudinal study $(N=619$ at T1). In this study, participants rated nine perceived characteristics of the same major life event up to five times within one year. We estimated rank-order and mean-level stabilities as well as intraclass correlations of these life event characteristics with continuous time models. Furthermore, we computed continuous time models for the stability of affective well-being and the Big Five personality traits to generate benchmarks for the interpretation of the stability of the life event characteristics. Rank-order stabilities for the life event characteristics were lower than for the Big Five, but higher than for affective well-being. Most of the variance in life event characteristics was explained by between-person differences. Furthermore, we found a significant mean-level increase for the life event characteristic change in world views and a significant decrease for extraordinariness. These mean-level changes are in line with the meaning-making literature and affective adaptation theory, whereas the rather high rank-order stability of the life event characteristics challenges the importance of reappraisal processes of major life events.
\end{abstract}

Word count: 250

Keywords: major life events, event characteristics questionnaire, rank-order stability, mean-level stability, continuous time models 


\section{Stability and Change of Perceived Characteristics of Major Life Events}

Major life events are relevant for various psychological outcomes. They have been associated with personality changes (Bleidorn et al., 2018; Lüdtke et al., 2011; Shiner et al., 2017; Specht, 2017), with changes in subjective well-being (Diener et al., 2006; Headey \& Wearing, 1989; Lucas, 2007; Luhmann et al., 2012; Mancini et al., 2011), and with the onset of mental disorders (Assari \& Lankarani, 2016; Beards et al., 2013; Berenbaum et al., 2008; Kendler et al., 2003; Paykel, 2003). In most studies, the occurrence of major life events was assessed categorically, that is, checklists were used to determine the type and the frequency of life events that the participants had experienced (Assari \& Lankarani, 2016; Berenbaum et al., 2008; Headey \& Wearing, 1989; Lüdtke et al., 2011; Shiner et al., 2017). This approach has been criticized because very different major life events can fall into the same checklist category and because interindividual differences in the perceptions of major life events are not taken into account (B. P. Dohrenwend, 2006; Luhmann et al., 2020; Redfield \& Stone, 1979). An alternative approach is to let participants rate their perceptions of major life events on different continuous dimensions, henceforward called life event characteristics, such as valence, predictability, or challenge (Ferguson et al., 1999; Kendler et al., 2003; Luhmann et al., 2020). These perceived event characteristics can be used as predictors of event-related changes in subjective-well-being, mental health, and other outcomes (e.g., Fassbender et al., 2021; Luhmann et al., 2020).

In the present paper, we focus on how perceived event characteristics change over time. Examining stability and change of event characteristics is important for several reasons. First, studies that have investigated the perceived event characteristics so far have asked the participants for their ratings at different time points after the major life event. In some studies, participants were asked to rate the perceived event characteristics some weeks after the event (Mitchell et al., 1997), in other studies months (Hasan \& Power, 2004; Nakai et al., 2014; Sheets et al., 1996) or even years after the event (Servaty-Seib, 2014). Currently, it is unclear how such 
temporal differences between studies affected the measured event characteristics and their associations with psychological outcomes. Second, findings on the stability and change of life event characteristics can help to further explore their nature (for a similar argument see Chung et al., 2014). A low stability could indicate that people's perceptions of life events are strongly determined by situational influences (Hammen, 2005; Schmidt et al., 1990), whereas a high stability could suggest that people have a stable mental presentation of a major life event which might be more strongly influenced by stable personality traits or enduring cognitive styles (Rakhshani et al., 2020). Third, if perceived event characteristics change over time, it should be investigated whether these changes are correlated with changes in psychological outcomes. For example, does life satisfaction change after a major life event because someone perceives the event positively or because their perceptions become more positive over time (Brose et al., 2020)?

To date, stability and change of perceived event characteristics have not yet been systematically investigated. The present paper therefore focuses on the following research questions: How rank-order stable are the perceived event characteristics over time? Are there mean-level changes in the perceived event characteristics? Are these changes more prominent in certain event characteristics? We addressed these questions using longitudinal data containing repeated ratings of perceived characteristics of the same major life event using the Event Characteristics Questionnaire (ECQ; Luhmann et al., 2020). We used continuous time models (CTMs) to estimate rank-order and mean-level stabilities as well as intraclass correlations of the perceived event characteristics (Driver et al., 2017; Voelkle et al., 2012). These models treat time continuously and allow identifying the generating process of change (Voelkle et al., 2012). Since CTMs are not yet widely used in psychology, we also applied these models to analyze the stability of personality and affective well-being. Their stability has been well examined (e.g., Borghuis et al., 2017; Lüdtke et al., 2011; Roberts \& DelVecchio, 2000; 
Watson \& Walker, 1996; Yap et al., 2014) so that these results can provide benchmarks for the interpretation of the stability of the perceived event characteristics.

\section{Major Life Events and Perceived Event Characteristics}

Major life events are defined as “events that are clearly timed, disrupt one's everyday routine, and are perceived as personally significant and memorable by those who experienced them" (Luhmann et al., 2020, p. 2). In most studies, major life events are assessed with checklists that list numerous event categories and ask participants to indicate whether they have experienced them or not (B. P. Dohrenwend, 2006). One example is the List of Threatening Experiences (Brugha et al., 1985) which includes 12 event categories such as "serious illness, injury or assault to self", or "major financial crisis". Other checklists are more fine-grained (e.g., PERI Life Events Scale, 102 event categories, B. S. Dohrenwend et al., 1978; Social Readjustment Rating Questionnaire, 43 event categories, Holmes \& Rahe, 1967). In most cases, either the experience of a single event or a sum score of experienced events is then used as predictor for outcomes such as life satisfaction, mental health, or personality change (Assari \& Lankarani, 2016; Berenbaum et al., 2008; Headey \& Wearing, 1989; Lüdtke et al., 2011; Shiner et al., 2017).

This approach has several disadvantages (see Luhmann et al., 2020, for a more detailed discussion). First, the variability within a category is neglected. For example, a major depressive disorder and an almost deadly virus infection are quite different life events falling into the same category "serious illness, injury or assault to self" (B. P. Dohrenwend, 2006; Hammen, 2005). Second, differences between categories are not explained. For example, in the List of Threatening Experiences (Brugha et al., 1985), "separation due to marital difficulties" and "broke off a steady relationship" are distinguished without justifying why and how these categories differ. Third, the same life event can be perceived differently by different people (Redfield \& Stone, 1979). For example, if a couple breaks up, one person might perceive this 
separation as a sudden, unforeseen, very negative event and for the other person it might be a relief that was long in coming.

To address these disadvantages, Luhmann et al. (2020) developed the Event Characteristics Questionnaire (ECQ). The ECQ is a dimensional taxonomy to assess nine perceived characteristics of major life events: valence (positivity or negativity of the event), impact (extent to which the event changed one's life), predictability (extent to how predictably the event had occurred), challenge (amount of stress and anxiety caused by the event), emotional significance (extent to which the event elicited strong feelings), change in world views (extent to which the event changed one's views), social status change (extent of negative changes in one's social status), external control (extent to which the event was controlled or caused by others), and extraordinariness (extent of how extraordinary the event was). The ECQ showed satisfactory reliability, convergent validity, and predictive validity (Luhmann et al., 2020).

\section{Stability and Change of Perceived Event Characteristics}

Various theories suggest that the perception of major life events can change over time. For example, appraisal theory (Lazarus \& Folkman, 1984) distinguishes between primary appraisal and reappraisal of an event. The term reappraisal explicitly describes a change in the primary appraisal (i.e., a change in the perception of an event). This change can be triggered by new information or it can be a form of cognitive coping, in which the past is reinterpreted in a more positive way. In a similar manner, reappraisal of events is seen as important strategy of emotion regulation (Ford \& Troy, 2019; Gross, 2002; Uusberg et al., 2019). Theories of posttraumatic growth also assume that the perceptions of stressful life events can change over time and that these changes are related to personality development (Jayawickreme \& Blackie, 2014; Park, 2010). Finally, affective adaptation theory (Wilson \& Gilbert, 2008) states that adaptation of affective well-being occurs (at least partly) because perceptions of an event change over time. More precisely, the authors propose that the affective response after a major life event 
decreases over time as people try to explain the event to themselves. Thus, the event is in hindsight interpreted as more predictable and ordinary. Although these theories suggest that the perceptions of major life events change over time and that these changes are important for personality development and well-being, empirically, little is known about the occurrence and time frame of these changes.

Stability and change of a construct can be examined in different ways. In the present paper, we investigated rank-order stability and mean-level stability as indicators of stability at an aggregated level. Both are conceptually and statistically independent of each other and suitable to investigate different questions (Borghuis et al., 2017; Roberts et al., 2006; Roberts \& DelVecchio, 2000). Rank-order stability indicates how much people change in their relative position within a sample over time (Bleidorn \& Hopwood, 2019; Roberts \& DelVecchio, 2000). Mean-level stability measures the direction and extent of absolute changes in a given construct averaged over all participants (Bleidorn \& Hopwood, 2019; Roberts et al., 2006). Another indicator related to the stability and change of constructs that we also examined in the present study is the ratio of between-person and within-person variance (Merz \& Roesch, 2011). This ratio indicates the relative importance of between-person differences and within-person changes.

\section{Rank-Order Stability of Perceived Event Characteristics}

Rank-order stability can be examined using test-retest correlations (e.g., the correlation between extraversion at time point one and extraversion at time point two) or autoregressive coefficients (e.g., the predictive effect of extraversion at time point one for extraversion at time point two). Test-retest correlations and autoregressive coefficients differ in their value range: test-retest correlations, like every correlation, have a fixed value range whereas autoregressive coefficients do not. However, for both measures, values between zero and one are usually expected in psychological research (Hamaker \& Grasman, 2014; Ryan et al., 2018). Another difference is the underlying causal assumption: Only autoregressive coefficients are based on a 
causal model and they indicate the carryover or predictive effect over time whereas test-retest correlations capture not only this direct carryover effect but may also be affected by other variables. Therefore, autoregressive coefficients are usually lower than test-retest correlations, and some authors argue that autoregressive coefficients are the preferable stability indicator (Dormann \& Griffin, 2015).

There are already some findings regarding test-retest correlations of perceived event characteristics (Ferguson et al., 1999; Frazier et al., 2011; Lewinsohn et al., 1985; Sarason et al., 1978). However, these correlations were used to estimate test-retest reliability rather than rank-order stability, so the retest intervals were rather short (between three weeks and three months; see Table 1). Furthermore, a test-retest correlation based on manifest variables does not account for measurement error and therefore confounds measurement error and actual change. For this reason, rank-order stability is typically determined using structural equation modeling (see below for details) (Chung et al., 2014). Despite these limitations, the previously published test-retest correlations can give an impression of rank-order stabilities over short intervals. If estimates of reliability are additionally available (e.g., Cronbach's alpha), a rankorder stability estimate adjusted for measurement error can be calculated (Röseler et al., 2020; Equation 2). Table 1 summarizes these existing findings on test-retest correlations of different life event questionnaires and, whenever possible, also gives a rank-order stability estimate adjusted for measurement error.

Overall, these findings show that there is a moderate to high rank-order stability of perceived event characteristics at least over short periods of time. However, research on other constructs has shown that rank-order stability decreases when the length of the retest interval increases (e.g., personality traits: Damian et al. 2019, Fraley and Roberts 2005, Caspi et al. 2005; intelligence: Gow et al. 2011; self-esteem: Trzesniewski et al. 2003, Anusic and Schimmack 2016; attitudes: Arsenian 1970). In this study, we therefore moved beyond these short retest intervals by investigating rank-order stabilities of perceived event characteristics 
over a period of approximately one year. We expected to observe a similar decrease of rankorder stabilities of perceived event characteristics with increasing length of the retest interval (Hypothesis 1).

\section{Table 1}

Test-retest correlations and estimated rank-order stability coefficients of perceived event characteristics assessed with questionnaires other than the ECQ

\begin{tabular}{|c|c|c|c|c|c|}
\hline & $\begin{array}{l}\text { Retest } \\
\text { interval }\end{array}$ & $\begin{array}{c}\text { Life event } \\
\text { characteristics }\end{array}$ & $\alpha$ & $r_{12}$ & $\begin{array}{c}\text { Estimated } \\
\text { stability }\end{array}$ \\
\hline \multirow{6}{*}{$\begin{array}{l}\text { Ferguson et al. } \\
\qquad(1999)\end{array}$} & \multirow[t]{3}{*}{1 month } & Threat & $.82^{\mathrm{a}}$ & .90 & 1.00 \\
\hline & & Challenge & $.87^{\mathrm{a}}$ & .86 & .99 \\
\hline & & Loss & $.75^{\mathrm{a}}$ & .77 & 1.00 \\
\hline & \multirow[t]{3}{*}{3 months } & Threat & $.82^{\mathrm{a}}$ & .49 & .60 \\
\hline & & Challenge & $.87^{\mathrm{a}}$ & .48 & .55 \\
\hline & & Loss & $.75^{\mathrm{a}}$ & .59 & .79 \\
\hline \multirow{6}{*}{$\begin{array}{l}\text { Frazier et al. } \\
\qquad(2011)\end{array}$} & \multirow[t]{3}{*}{3 weeks } & Past control & $.88 / .89$ & .80 & .90 \\
\hline & & Present control & $.79 / .86$ & .59 & .72 \\
\hline & & Future control & $.88 / .90$ & .79 & .89 \\
\hline & \multirow{3}{*}{$\begin{array}{l}4 \text { to } 6 \\
\text { weeks }\end{array}$} & Past control & $.82-.86$ & .76 & $.88-.93^{\mathrm{b}}$ \\
\hline & & Present control & $.77-.82$ & .48 & $.59-.62^{b}$ \\
\hline & & Future control & $.80-.84$ & .67 & $.79-.84^{\mathrm{b}}$ \\
\hline $\begin{array}{l}\text { Lewinsohn et al. } \\
\quad \text { (1985) }\end{array}$ & 1 month & Aversiveness & $.76-.93$ & $.60-.80$ & \\
\hline \multirow{2}{*}{$\begin{array}{l}\text { Sarason et al. } \\
\text { (1978) }\end{array}$} & 5 to 6 & Positive change & & .53 & \\
\hline & weeks & Negative change & & .88 & \\
\hline
\end{tabular}

Note. Stability was estimated according to Röseler et al. (2020), Equation 2.

${ }^{a}$ Information was derived from a different sample than the test-retest correlation, so the calculated stability may be inaccurate. ${ }^{b}$ Since only a range was specified for internal consistency in this study, only a range could be calculated for the stability estimator.

\section{Mean-Level Stability of Perceived Event Characteristics}

To the best of our knowledge, the mean-level stability of perceived event characteristics has not yet been empirically investigated. Therefore, this study provides first results on whether there are mean-level changes in the trajectories of life event characteristics (i.e., an increase or decrease over time). Based on theoretical considerations and empirical findings from other 
fields of research, we had some expectations on how the perceived event characteristics extraordinariness, predictability, and valence might change over time.

As described above, affective adaptation theory (Wilson \& Gilbert, 2008) states that an event triggers a weaker emotional response over time because it is "explained away". By this, the authors refer to some higher order iterative mental process of finding explanations for an event so that it is perceived as more predictable and less exceptional. Accordingly, we assumed that perceived extraordinariness of major life events decreases, and that perceived predictability increases over time (Hypotheses 2 and 3). Findings on hindsight bias, which show that an event is retrospectively judged as more predictable, also fit this assumption (Fessel et al., 2009; Fischhoff \& Beyth, 1975; Hawkins \& Hastie, 1990). However, it should be noted that hindsight bias is usually tested by comparing participants' ratings of the likelihood of an event before and after the event occurred. In this study, perceived event characteristics were only assessed at different time points after the event. Nonetheless, there is research suggesting that hindsight bias needs some time to develop and that the perceived predictability of an event increases with increasing temporal distance from this event (Blank et al., 2008; Bryant \& Brockway, 1997; Bryant \& DeHoek, 2006; Bryant \& Guilbault, 2002).

Another memory bias that could explain how the perception of a life event characteristic changes over time is the positive memory bias or "rosy view" (Adler \& Pansky, 2020). According to the positive memory bias, healthy individuals remember autobiographical events more positively in retrospect and forget negative emotions more quickly than positive ones (Adler \& Pansky, 2020; Mitchell et al., 1997; Olson \& Zanna, 2013; Sedikides \& Skowronski, 2020; Walker \& Skowronski, 2009). Based on findings on positive memory bias, we expected the perceived valence of an event to become more positive over time (Hypothesis 4).

\section{Ratio of Between-Person and Within-Person Variance}

Between-person variance refers to the variability that can be attributed to differences between individuals. Within-person variance quantifies changes of a construct within 
individuals over time. Test-retest correlations as indictors of rank-order stability have been criticized since they mix these two types of variance (Cicchetti, 1994; Wagner et al., 2019). This criticism applies also to our estimation of rank-order stability using autoregressive coefficients. For this reason, we additionally computed intraclass correlations that estimate how much of a construct's total variance can be attributed to between-person differences. Higher intraclass correlations are an indicator of a higher stability since between-person differences are then more important than within-person fluctuations (Andreassen, 2016). In principle, similar results can be expected for intraclass correlations and rank-order stability: If there is no within-person variance (i.e., individuals do not change over time), there should be no changes in rank orders (maximum rank-order stability). However, if every participant changes equally over time, say, all participants become one scale point more extraverted, rank-order stability will still be at its maximum although there are within-person fluctuations. Thus, intraclass correlation and rank-order stability provide different information about stability and change of a construct.

\section{Statistical Methods for Estimating Stability and Change}

The statistical methods for estimating stability and change of constructs have evolved over the last decades. Older studies were based on the investigation of manifest variables using test-retest correlations and repeated measures ANOVA (e.g., Arsenian, 1970; Costa et al., 2000; Crawford et al., 1986; Gustavsson et al., 1997; Watson \& Walker, 1996). As mentioned above, these results can be distorted by measurement error (Borghuis et al., 2017; Watson, 2004). Modern approaches therefore use statistical methods for latent variables such as structural equation modeling.

Structural equation modeling allows separating the true (common) variance of a construct and the error variance (Little, 2013a; Ullman \& Bentler, 2006). Latent growth curve models are frequently applied to evaluate mean-level stability within the context of structural equation modeling (Bleidorn et al., 2009; Borghuis et al., 2017; Chung et al., 2014; van 
Scheppingen et al., 2018). In latent growth curve models, a latent intercept and a latent slope are modeled to describe the average change of a construct over time. Latent growth curve models allow modeling both linear and non-linear changes (Little, 2013a) and time can be explicitly included in these models. In contrast to mean-level stability, rank-order stability is often estimated by using first-order autoregressive models in which the autoregressive coefficient serves as an estimate of stability (Borghuis et al., 2017; Chung et al., 2014). In these models, time is usually only considered implicitly by the order of measurement occasions which makes it difficult to account for unequally spaced time intervals (Voelkle et al., 2012).

In the present study (as in many panel studies), the time intervals between the measurement occasions varied between and within participants. If not adequately accounted for, these unequal temporal distances lead to a distorted estimation of autoregressive parameters since those parameters are time-interval dependent (Kuiper \& Ryan, 2018; Voelkle \& Oud, 2013). One way to deal with unequally spaced time intervals between the measurement occasions is the use of continuous time models $(\mathrm{CTMs})^{1}$. As used here, CTMs are estimated in context of structural equation modeling. These models treat time continuously and thus describe the change of a construct over time accurately even if the time intervals differ within a study (Voelkle et al., 2012; Voelkle \& Oud, 2013; Voelkle \& Wagner, 2017). Traditional models for longitudinal data analysis (e.g., cross-lagged panel models or latent change score models) provide estimates of a change process for specific time intervals (e.g., the autoregressive effect of extraversion for an interval of three months). In contrast, CTMs can be used to investigate the generating process of change, that is, that they use the available information to identify the underlying function of the parameter of interest (e.g., the function of the autoregressive effect

\footnotetext{
${ }^{1}$ Some helpful references to understand CTMs in more detail are: Voelkle et al. (2012) for a comprehensive introduction of CTMs in context of psychology; Voelkle and Oud (2015) for a comparison of latent change score models and CTMs; de Moor et al. (2021), Mueller et al. (2018), and Wagner et al. (2018) as examples of the use of CTMs in context of personality psychology.
} 
of extraversion). With this function, it is possible to compute the autoregressive effect for any time interval of interest. Overall, CTM is a useful and flexible method to investigate the stability and change of a construct over time.

By using CTMs, unequally spaced measurement occasions turn into a strength of the study as they deliver information about the change of a construct at many different time points, and this information can help identify the generating process of change (Voelkle \& Oud, 2013). In this study, their use was especially important because besides the unequally spaced measurement occasions due to our sampling procedure (see below), CTMs also account for unequal temporal intervals between the event occurrence and the first measurement occasion. Furthermore, it can be assumed that most psychological constructs (including perceived event characteristics undergo continuous changes for which it is reasonable to model change continuously (Deboeck, 2013; Hecht \& Voelkle, 2021; Ryan et al., 2018).

Since CTMs are not yet widely used in psychology (Deboeck, 2013; Voelkle et al., 2012; Wagner et al., 2019), we explain them in detail in the section 'Data Analysis' below. To facilitate the interpretation of the findings of stability and change of perceived event characteristics, we also computed CTMs for measures of personality and affective well-being as their stability has been well examined (Lüdtke et al., 2011; Roberts \& DelVecchio, 2000; Vaidya et al., 2008; Watson \& Walker, 1996). According to the meta-analysis by Anusic and Schimmack (2016), these two constructs are quite representative of the range of rank-order stabilities of psychological constructs, with personality being among the most stable constructs and affective well-being being relatively volatile.

\section{The Present Study}

In this longitudinal study, a sample of young adults rated the perceived characteristics of a major life event they had recently experienced with the ECQ up to five times within one year. This design allowed us to examine how their perceptions of the characteristics of the same major life event changed over time. We examined stability and change in these perceived event 
characteristics in different ways to answer three research questions. (1) How stable are individual differences in the perceived event characteristics (rank-order stability)? In particular, we were interested in whether life event characteristics differed in their rank-order stability and in how stable the rank orders of life event characteristics were compared to the rank orders of affective well-being and personality traits. We expected rank-order stabilities of the life event characteristics to decrease with increasing length of the retest interval (Hypothesis 1). (2) Does the average perception of certain life event characteristics change over time (mean-level stability)? We expected perceived predictability and valence to increase, and perceived extraordinariness to decrease over time (Hypotheses 2 to 4). (3) What percentage of the total variance of life event characteristics can be explained by between-person differences (intraclass correlation)? Is this amount of variance similar to the ones of affective well-being or personality traits? We had no directed hypothesis for this research question.

\section{Methods}

The data for this paper came from the What's NEXT? Study, a five-wave longitudinal panel study conducted in 2018 and 2019. Data from the What's NEXT? Study were already used by Fassbender et al. (2021), Fassbender and Luhmann (2021), Kritzler et al. (2021), and Luhmann et al. (2020), but these publications did not investigate stability or change of perceived event characteristics. Data collection was approved by the local ethics committee of [INSTITUTION BLINDED FOR PEER REVIEW]. The preregistration of the study design is provided at [LINK BLINDED FOR PEER REVIEW; A PDF FILE OF THE PUBLISHED PREREGISTRATION IS PROVIDED IN THE SUPPLEMENTAL MATERIAL]. The preregistration for the analyses presented in this paper can be retrieved from https://osf.io/urqdw/?view_only=e97f3517abe8466fb5a1a9dcb430f908. Deviations from this preregistration are summarized in the supplemental material (Table S1). 


\section{Research Design}

The What's NEXT? Study primarily addressed young adults who had graduated from high school or university in Summer 2018. This target group was selected because major life events are particularly likely to occur after life transitions such as graduation (Lüdtke et al., 2011). Participants first registered for the study, provided an email address, informed consent, and they verified their age (minimum age 18 years). After this registration, they were invited to complete an online survey five times (henceforward referred to as T1 to T5) within one year (i.e., 0, 12, 24, 36, and 48 weeks after registration). Participants were invited to all online surveys, regardless of whether they had participated at the previous measurement occasion, unless they unsubscribed from the study. Thus, there were participants with missing data on some assessments (including T1). We asked participants to complete the surveys within two weeks after receiving the email invitations, but there was no limit on the time in which they were able to respond to an invitation. Consequently, some participants followed our invitation immediately and others after several weeks, so that the time intervals between the measurement occasions were not equal for all participants (Table 2).

At T1, participants freely named the most important major life event that had occurred in the last three months and rated it with the ECQ. At T2, participants were shown the event they had named at T1 and were asked to rate it again with the ECQ. At T3 and T4, only a randomly selected subsample of participants rated the T1 event with the ECQ again ${ }^{2}$. This design resulted in planned missing values for the ECQ at T3 and T4 which can easily be handled with CTMs, since these missing values "may simply be conceptualized as instances of unequal time intervals" (Mueller et al., 2018, p. 1132). At T5, all participants were asked to re-rate the T1 event with the ECQ. In addition to the ECQ, other questionnaires including the ones

\footnotetext{
${ }^{2}$ The other participants rated events that had occurred between the other measurement occasions which we did not analyze here.
} 
assessing personality or well-being were also administered at each measurement occasion (see the study-design preregistration for a complete list of all questionnaires).

\section{Table 2}

Information on demographic characteristics and temporal distances between the measurement occasions

\begin{tabular}{|c|c|c|c|c|c|c|}
\hline & \multicolumn{2}{|c|}{ Demographic characteristics } & \multicolumn{4}{|c|}{$\begin{array}{l}\text { Temporal distance to the next measurement } \\
\text { occasion (in weeks) }\end{array}$} \\
\hline & $\%$ female & $\begin{array}{c}\% \text { high school } \\
\text { graduation }\end{array}$ & $M$ & $S D$ & Min & $\operatorname{Max}$ \\
\hline $\mathrm{T} 1$ & 72.54 & 92.57 & 12.94 & 1.19 & 4.06 & 19.60 \\
\hline $\mathrm{T} 2$ & 76.00 & 92.24 & 12.08 & 1.20 & 6.29 & 21.06 \\
\hline $\mathrm{T} 3$ & 76.52 & 92.82 & 12.09 & 0.98 & 8.66 & 18.34 \\
\hline $\mathrm{T} 4$ & 75.61 & 92.99 & 12.16 & 1.02 & 7.22 & 18.18 \\
\hline T5 & 76.10 & 93.08 & & & & \\
\hline
\end{tabular}

Note. The average temporal distance between the major life event named by the participants and T1 was 6.78 weeks $(S D=3.85$, Range $=0-15)$.

\section{Participants}

Participants were recruited via social media platforms as well as at introductory events at universities. As compensation for participation and to reduce dropout, vouchers with increasing values were raffled after each measurement occasion.

A total of 857 people registered to take part in this panel study. To ensure data quality, we excluded all participants with incorrect or missing answers on two instructed response items (see below) and participants who completed the online questionnaires in less than ten minutes (40\% of expected duration). Furthermore, only participants who named and rated an event at T1 that had occurred in the last 15 weeks (i.e., within the requested time frame) were included in our analyses. Overall, this procedure resulted in the following sample sizes: $N_{T 1}=619$, $N_{T 2}=430, N_{T 3}=364, N_{T 4}=331$, and $N_{T 5}=321$. Participants' mean age at T1 was 21.48 years $(S D=4.05)$. More details on the demographic characteristics of the sample are displayed in Table 2. 


\section{Measures}

Items of the scales were presented in randomized order. Mean scores were calculated for descriptive purposes.

\section{Naming a Major Life Event and Timing of the Event}

At T1, participants could freely name a major life event that had occurred in the last three months before T1. The instruction included information on the definition of major life events (personally relevant, clearly timed). To provide more information on the named events, we created a word cloud of the free-text answers and coded the events into event categories (see supplemental material for details). In addition, participants were asked to indicate how many weeks ago the event occurred.

\section{Big Five Personality Traits}

The Big Five personality traits (agreeableness, conscientiousness, extraversion, neuroticism, and openness) were measured with the German 15-item version of the BFI-2-XS (Rammstedt et al., 2018; Soto \& John, 2017). Items were rated on a 5-point scale ranging from 1 (strongly disagree) to 5 (strongly agree). Responses were reversed if appropriate.

\section{Affective Well-Being}

Affective well-being was assessed with the German six-item version of the Scale of Positive and Negative Experiences (SPANE; Diener et al., 2010; Rahm et al., 2017). Participants were asked to rate how often they felt a certain way (e.g., "happy") within the last month. Items were rated on a 5-point scale ranging from 1 (very rarely or never) to 5 (very often or always). Responses were reversed if appropriate so that all items indicate higher affective well-being.

\section{Event Characteristics Questionnaire}

The ECQ (Luhmann et al., 2020) was used to assess perceived characteristics of the major life event (items as in Study 5 in Luhmann et al., 2020). Items were rated on a 5-point scale ranging from 1 (not true at all) to 5 (absolutely true). The ECQ measures nine life event 
characteristics: valence (6 items, e.g., "The event was joyful"), challenge (4 items, e.g., "The event was stressful"), extraordinariness (3 items, e.g., "Few people like me experience such an event in their lives"), predictability (4 items, e.g., "The event was predictable"), external control (4 items, e.g., "The event was in other people's hands"), emotional significance (4 items, e.g., "The event elicited strong feelings"), change in world views (4 items, e.g., "The event changed my views"), impact (4 items, e.g., "The event had a strong impact on my life"), and social status change (4 items, e.g., "The event threatened my social status"). Responses were reversed if appropriate.

\section{Instructed Response Items}

Each survey included two instructed response items (Meade \& Craig, 2012) such as "In order to secure the data quality, please select the response option often". Participants with false or no answer on these items were excluded.

\section{Data Analysis}

All analyses were conducted in $\mathrm{R}$ (version 4.0.2). The R scripts for our analyses can be retrieved from https://osf.io/urqdw/?view_only=e97f3517abe8466fb5a1a9dcb430f908. We used CTMs to answer our research questions and to test our hypotheses. These analyses were conducted with $\mathrm{R}$ packages ctsem and ctsemOMX (Driver et al., 2017). We used a level of significance of $\alpha=.05$ for hypothesis testing.

\section{General Information on Continuous Time Models}

We applied CTMs via structural equation modeling. As in classical structural equation modeling, a latent factor is modeled which is free of measurement error. This latent factor is also referred to as latent process since its level and relation to other constructs is continuously monitored over time (Voelkle et al., 2012; Voelkle et al., 2018). 
To understand CTMs, one has to distinguish continuous and discrete time parameters ${ }^{3}$. Other methods to model longitudinal data (e.g., latent change score models or cross-lagged panel models) usually provide discrete time parameters which describe the relationship between two variables at a certain point in time (e.g., the autoregressive effect of valence for an interval of three months). In contrast, continuous time parameters determine the underlying function of the discrete time parameters. In CTMs, these continuous time parameters are calculated based on stochastic differential equations (Voelkle et al., 2012). The interpretation of continuous time parameters can be difficult without a deeper understanding of these differential equations. However, continuous time parameters offer the advantage that they can be used to determine the discrete time parameters for any time interval.

With CTMs, the following continuous time parameters are calculated: the drift matrix, the diffusion matrix, and continuous time intercept(s). For this study, the drift matrix is the most important part of CTMs as it includes the parameters that describe the temporal dynamics of latent processes (Driver \& Voelkle, 2018a). In our case, since we use CTMs with only one latent process, the drift matrix has only one element: an auto-effect. This auto-effect can be used to determine discrete time autoregressive effects for any time interval (Driver \& Voelkle, 2018a; Voelkle et al., 2012). For example, the continuous time auto-effect for extraversion can be used to compute the autoregressive effect for extraversion for an interval of three, five, or twelve months (see Voelkle et al., 2012 for equations).

\section{Using Continuous Time Models to Answer the Research Questions and Test the Hypotheses}

In our analyses, we applied CTMs based on first-order stochastic differential equations with only one latent process (one model for each life event characteristic). To obtain benchmarks for interpretation, we also computed the same models for the Big Five personality

\footnotetext{
${ }^{3}$ To distinguish discrete time and continuous time parameters in equations and results, we label discrete-time parameters with an asterisk (*).
} 
traits and affective well-being. First-order CTMs assume that there is a single generating process of change (Ryan et al., 2018; Voelkle et al., 2012). In this kind of model, a negative continuous time auto-effect indicates that the latent process is reverting to an equilibrium position (asymptotically stable process; Voelkle \& Oud, 2013). For example, if the major life event caused an immediate increase in affective well-being, a first-order CTM with a negative continuous time auto-effect implies that affective well-being will revert to a stable long-term mean level (i.e., equilibrium position) over time. We chose this kind of modeling because it seemed reasonable to assume that the perceived event characteristics, personality traits, and affective well-being change in such a manner after a major life event. This assumption is also supported by existing equilibrium theories for well-being and personality traits (for an overview see Luhmann \& Intelisano, 2018; Ormel et al., 2017). However, other dynamics can also be modeled with the employed first-order stochastic differential equations. For example, a positive continuous time auto-effect would indicate an explosive process that is not reverting to an equilibrium position but is repelled from it (Ryan et al., 2018).

To answer our first research question regarding the rank-order stabilities of the life event characteristics, we examined the continuous time auto-effect $a$. As outlined above, we expected this coefficient to be negative. In this case, values closer to zero indicate a higher rank-order stability of a construct (Driver \& Voelkle, 2018a; Ryan et al., 2018). Furthermore, values closer to zero indicate a smaller decline in discrete time autoregressive coefficients with increasing length of the retest interval. A value of exactly zero means that the discrete time autoregressive coefficient equals one for any time interval (i.e., no decline of rank-order stability). Thus, results would be consistent with Hypothesis 1 (decline of rank-order stability with increasing length of the retest interval) if the confidence interval of the continuous time auto-effect included only negative values. Furthermore, we computed and plotted the more interpretable discrete time autoregressive coefficients for time intervals of up to 15 months (which approximately equals 
the temporal distance between the event occurrence and the last measurement occasion) to address Research Question 1.

Regarding the mean-level stability of the life event characteristics (Research Question 2 and Hypotheses 2 to 4), we examined the mean level of the latent process. We computed and plotted this mean level over an interval of 15 months. Additionally, we calculated an effect size for mean-level change over 15 months $\left(E S_{15}\right)$ for all nine life event characteristics, the Big Five personality traits, and affective well-being:

$$
\mathrm{ES}_{15}=\frac{\mu_{\eta 15}^{*}-\mu_{\eta 0}^{*}}{\sqrt{\mathrm{q}_{0}^{*}}}
$$

$\mu_{\eta 0}^{*}($ TOMean $)$ and $q_{0}^{*}$ (TOVar) indicate the mean level and the variance of a latent process at time point zero and can be seen as starting values of the latent process (Driver \& Voelkle, 2018). We also tested the statistical significance of mean-level changes for a certain life event characteristic by comparing the model fit of two nested CTMs (Driver et al., 2017). In the first (restricted) model, it was assumed that the latent process is already in its equilibrium position ( $\mu_{\eta 0}^{*}$ is restricted to stationarity). Thus, in this restricted model, no mean-level changes are allowed. In the second (unrestricted) model, the parameter $\mu_{\eta 0}^{*}$ was freely estimated and may thus deviate from the equilibrium position, so that there may be mean-level changes in the latent process. The two nested models were compared with a likelihood ratio test ( $\Delta-2 L L)$ and by examining the change in Akaike's information criteria ( $\triangle \mathrm{AIC})$. Mean-level changes were interpreted as significant if $\Delta \mathrm{AIC}>4$ and if the likelihood ratio test was significant (de Moor et al., 2021). Using this procedure, we could examine whether there were overall mean-level changes in the process with the passing of time. However, it should be noted that not all forms of mean-level changes can be identified using this procedure (e.g., a big oscillation; Driver \& Voelkle, 2018b).

Regarding Research Question 3 (ratio of between-person and within-person variance), we computed intraclass correlations for the perceived event characteristics, affective well- 
being, and the Big Five personality traits. The intraclass correlations indicate how much of the total long-range process variance is explained by between-person differences (Hecht \& Voelkle, 2021):

$$
\mathrm{ICC}=\frac{\sigma_{\mathrm{b} \infty}^{2}}{\sigma_{\mathrm{b} \infty}^{2}+\mathrm{q}_{\infty}^{*}}
$$

To calculate such an intraclass correlation, we estimated CTMs with random intercepts (see next section for more details). $\sigma_{b \infty}^{2}$ is the long-range variance of the continuous time intercept and thereby a measure of between-person differences in the long range (i.e., between-person variance when the time interval approaches infinity). $q_{\infty}^{*}$ is the asymptotic diffusion variance and indicates the within-person variance in the long range (i.e., within-person variance when the time interval approaches infinity $)^{4}$.

\section{Details on Model Specification}

The specification of our model is illustrated in Figure 1, and the model equations are provided in the supplemental material (Figure S2). CTMs were applied in the same way to all nine life event characteristics, the Big Five, and affective well-being. The latent process was scaled using the indicator variable method, that is, the factor loading of the first indicator was fixed to one and its mean to zero. All other means of the manifest indicators and factor loadings were freely estimated. We used single items as indicators, except for valence and affective wellbeing. These two constructs were measured with six items, allowing us to create three item parcels with two items each as recommended by Little (2013b). All continuous time parameters

\footnotetext{
${ }^{4}$ Note that the estimates of the intraclass correlations of CTMs might not be directly comparable to the ones computed using mixed models. With CTMs, we were estimating how much of the "long-range variance" is attributable to between-person differences. These long-range estimates can be interpreted as "expectations about the estimated process, independent of any measurements" (Hecht et al., 2019; p. 536). In contrast, intraclass correlations computed with mixed models are not independent of the measurements but are calculated based on observed scores.
} 
(drift matrix, diffusion matrix, continuous time intercept) were freely estimated. In addition, we freely estimated the initial variance $\left(q_{0}^{*} ;\right.$ TOVAR $)$ and the initial mean $\left(\mu_{\eta 0}^{*} ;\right.$ TOMEAN) of the latent process - with the exception that the initial mean was restricted to stationarity in model comparisons to test significance of mean-level changes. Regarding the coding of time, we set the time point at which the event occurred to zero and computed the individual distances (in weeks) between this starting point and the measurement occasions for every participant.

\section{Figure 1}

\section{Illustration of model specification in our case}

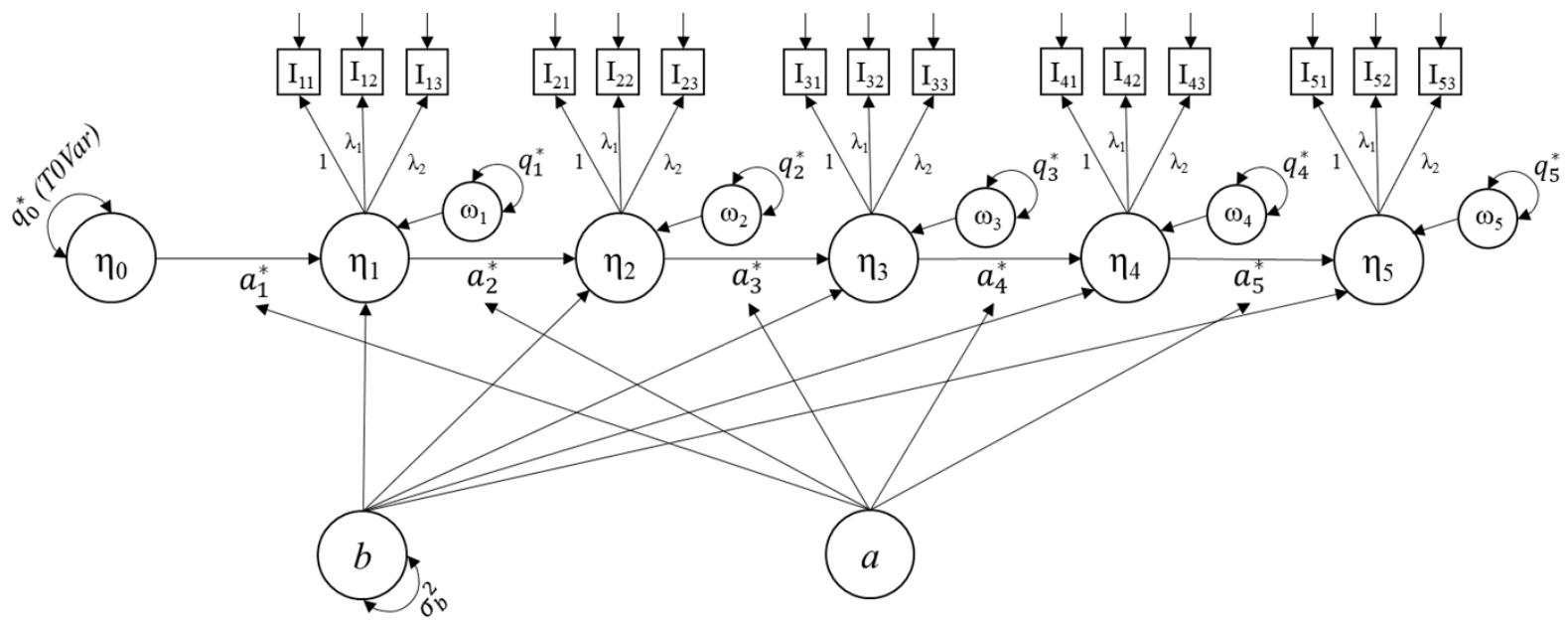

Note. To keep the figure parsimonious, we did not include illustrations of means. $\sigma_{b}^{2}$ was only estimated in the random-intercept model to answer Research Question 3; in the other models, this variance was fixed to zero. $a$ represents the continuous time auto-effect and $b$ the continuous time intercept. Asterisks $\left(^{*}\right)$ indicate discrete time parameters. Some elements of this illustration are adapted from Hecht and Zitzmann (2020) and Wagner et al. (2018).

In the models addressing Research Question 3, random intercepts were included to distinguish between-person and within-person variability ${ }^{5}$ (Voelkle et al., 2018; Wagner et al., 2019). In the models addressing Research Questions 1 and 2, in contrast, the intercept was fixed for two reasons. First, with a fixed intercept, the autoregressive drift coefficient reflects both

\footnotetext{
${ }^{5}$ In contrast to the fixed-intercept models, we computed the random-intercept models using the $c t$ StanFit-function (Driver \& Voelkle, 2018a) which allows random effects for all intercept-related parameters (TOMean, $b$, and manifest means).
} 
within-person and between-person changes (which allows the desired rank-order stability interpretation). Second, models with fixed intercepts are more parsimonious and may lead to more consistent results than models with random intercepts (de Moor et al., 2021).

\section{Measurement Invariance and Required Sample Sizes for Continuous Time Models}

Although the assumption of measurement invariance can be relaxed for CTMs (Driver, 2020), we applied CTMs in a way that requires measurement-invariant items over time. We tested this assumption using the R packages lavaan (Rosseel, 2012) and semTools (Jorgensen et al., 2020). More details on the model specification and the results are reported in the supplemental material (Table S7). All scales except the subscale agreeableness of the Big Five and the ECQ subscale impact showed strong measurement invariance. For these two subscales, the covariance matrix of the latent factors was not positive definite. Since stability and change of agreeableness were not the main focus of the present paper, we did not consider it in the CTMs. For the ECQ subscale impact, we were able to achieve strict measurement invariance by dropping the item with the largest modification index.

Regarding the required sample size for CTMs, a simulation study by Hecht and Zitzmann (2020) indicated that for a design like ours with five measurement occasions, 250 to 500 people might be sufficient for good model performance. We thus assumed that our sample size was sufficient to compute univariate CTMs. However, a word of caution is needed since these simulations are based on many other assumptions (e.g., the range of true parameter values) and it is difficult to generalize their findings beyond the investigated conditions (Hecht \& Zitzmann, 2020).

\section{Problems with Estimation of Continuous Time Models}

Not all CTMs converged right away. Therefore, we followed our preregistered statistical back-up plan to improve model estimations. First, we changed the coding of time. Although CTMs in general allow computing discrete time parameters for any arbitrary time interval, the coding of time is relevant for model estimation. Model estimation is improved if a time scale is 
chosen "that roughly matches the expected dynamics" (Driver et al., 2017, p. 27). With time coded in months, all models for the life event characteristics except impact and the model for affective well-being converged. For the Big Five and the life event characteristic impact, which seemed to be more stable, we had to code time in units of six months. However, estimates can easily be converted between the different time scales so that the presented results and the created graphs can be directly compared across all constructs.

Second, we had some estimation problems with the random-intercept models for the Big Five personality traits. Initially, we had planned to include a random effect for the continuous time intercept only. However, the random-intercept models for the Big Five only converged when including random effects for all intercept-related parameters (TOMean, $b$, and manifest means). To obtain comparable results, we computed all random-intercept models in this way. In general, the results for the different Big Five personality traits were then very similar to each other so that, in the following, we only report findings on openness. Results for the other Big Five traits are presented in the supplemental material (Tables S8 and S9).

\section{Results}

\section{Descriptive Statistics}

Descriptive statistics and internal consistencies for all scales are reported in the supplemental material (Tables S2 to S5). Figure 2 depicts individual growth trajectories for the nine life event characteristics for 75 randomly selected participants. Two aspects about this figure should be noted: First, there are pronounced between-person differences in the perceived event characteristics; second, at least for some individuals, there are considerable changes in event perceptions over time.

Regarding the events that the participants named at T1, it can be summarized that these events were mostly positive and that they can be seen as typical for a sample of young university students. The event categories that the participants named most frequently were vacation $(N=52)$, starting college $(N=48)$, relocation $(N=47)$, and Abitur (German high school 
diploma; $N=46$ ). More details on the event categories and the free-text answers of the participants are presented in the supplemental material (Table S6 and Figure S1).

\section{Figure 2}

\section{Individual growth trajectories of 75 randomly selected participants}
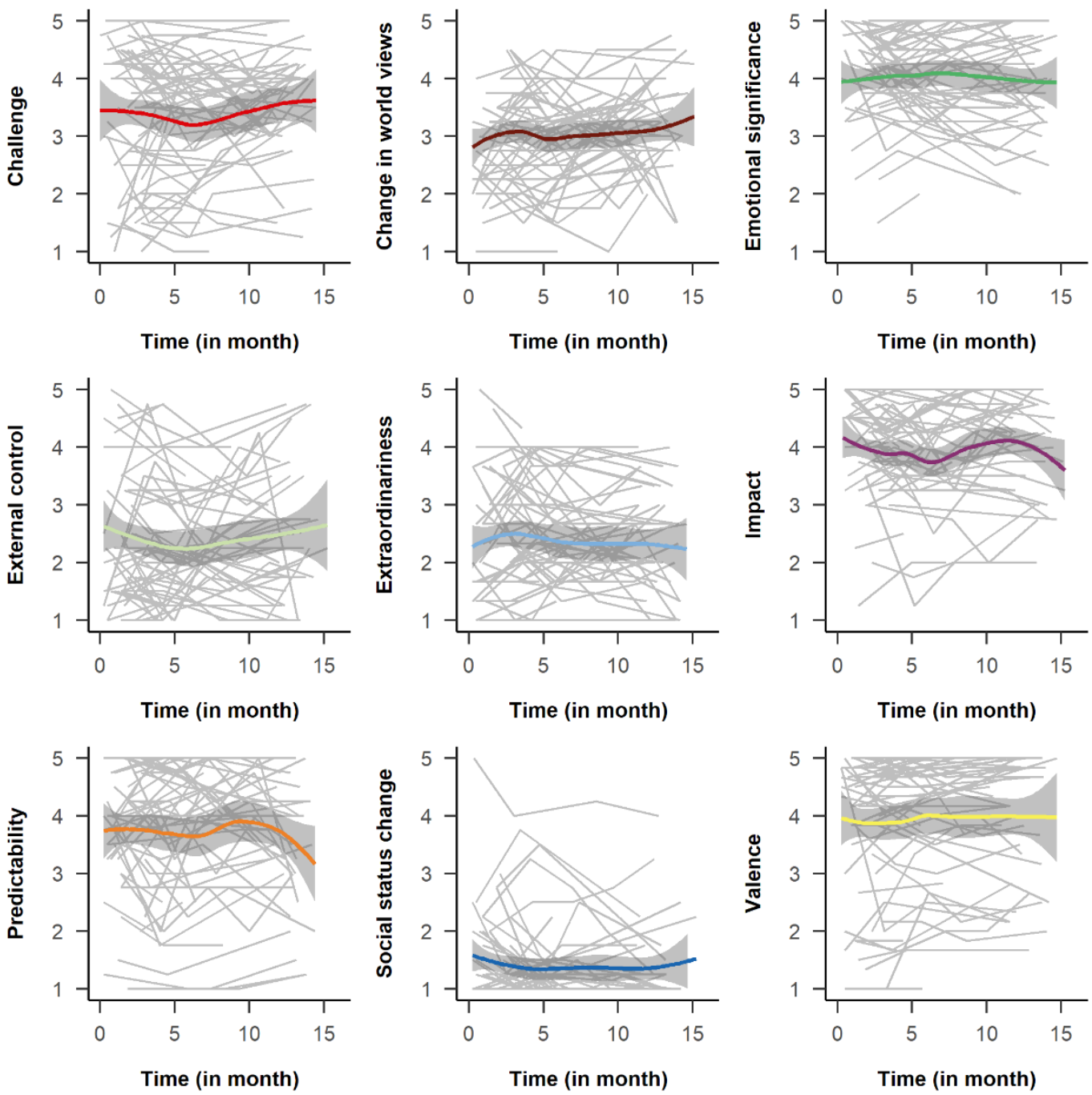

Note. Growth trajectories for the nine life event characteristics of 75 randomly selected participants including LOESS curve with confidence interval.

\section{Rank-Order Stability}

Rank-order stability indicates how much people change in their relative position within a sample over time. Our first research question was whether the life event characteristics differed in their rank-order stability and how stable the rank orders of the life event characteristics were compared to the rank orders of affective well-being and personality traits. 
Furthermore, we hypothesized that the rank-order stabilities of the life event characteristics decrease with increasing retest interval (Hypothesis 1). To evaluate Hypothesis 1 and Research Question 1, Table 3 shows the continuous time auto-effect $(a)$ as well as the one-month $\left(a_{1}^{*}\right)$ and twelve-months $\left(a_{12}^{*}\right)$ discrete time autoregressive parameters for all life event characteristics, openness, and affective well-being. The change of discrete time autoregressive coefficients over time is also depicted in Figure 3. In the following, the main findings of these analyses are summarized.

\section{Table 3}

Model fit, continuous time auto-effects, and discrete time autoregressive parameters for the life event characteristics, openness, and affective well-being

\begin{tabular}{|c|c|c|c|c|c|}
\hline & \multicolumn{2}{|c|}{$\begin{array}{c}\text { Continuous time } \\
\text { auto-effects }\end{array}$} & \multicolumn{2}{|c|}{$\begin{array}{c}\text { Discrete time } \\
\text { autoregressive effects }\end{array}$} & \multirow{2}{*}{$\begin{array}{l}\text { Model fit } \\
(-2 \mathrm{LL})\end{array}$} \\
\hline & $a$ & $95 \% \mathrm{CI}$ & $a_{1}^{*}$ & $a_{12}^{*}$ & \\
\hline Challenge & -0.030 & {$[-0.041,-0.027]$} & 0.971 & 0.698 & 17071.57 \\
\hline Change in world views & -0.038 & {$[-0.054,-0.023]$} & 0.963 & 0.634 & 17217.37 \\
\hline Emotional significance & -0.020 & {$[-0.032,-0.018]$} & 0.980 & 0.783 & 15387.05 \\
\hline External control & -0.022 & {$[-0.036,-0.010]$} & 0.978 & 0.763 & 18574.44 \\
\hline Extraordinariness & -0.019 & {$[-0.032,-0.008]$} & 0.981 & 0.793 & 12769.53 \\
\hline $\operatorname{Impact}^{\mathrm{a}}$ & 0.010 & {$[0.002,0.017]$} & 1.010 & 1.124 & 13905.75 \\
\hline Predictability & -0.028 & {$[-0.038,-0.026]$} & 0.972 & 0.711 & 16224.65 \\
\hline Social status change & -0.040 & {$[-0.054,-0.026]$} & 0.961 & 0.622 & 12328.93 \\
\hline Valence & -0.023 & {$[-0.030,-0.022]$} & 0.977 & 0.755 & 9072.07 \\
\hline Openness $^{\mathrm{a}}$ & -0.002 & {$[-0.010,0.005]$} & 0.998 & 0.977 & 15646.28 \\
\hline Affective well-being & -0.141 & {$[-0.165,-0.118]$} & 0.869 & 0.185 & 10502.89 \\
\hline
\end{tabular}

Note. $a=$ continuous time auto-effect; $\mathrm{CI}=$ confidence interval; $a_{1}^{*}=$ one-month discrete time autoregressive parameter; $a_{12}^{*}=$ twelve-month discrete time autoregressive parameter; $-2 \mathrm{LL}=-2$ Log-Likelihood.

${ }^{\text {a }}$ Estimates for openness and impact were computed using a coding of time in units of six months to improve model estimation but were then converted so that the results are now directly comparable to the results of the other scales. 


\section{Figure 3}

Discrete time autoregressive coefficients for different lengths of the retest interval

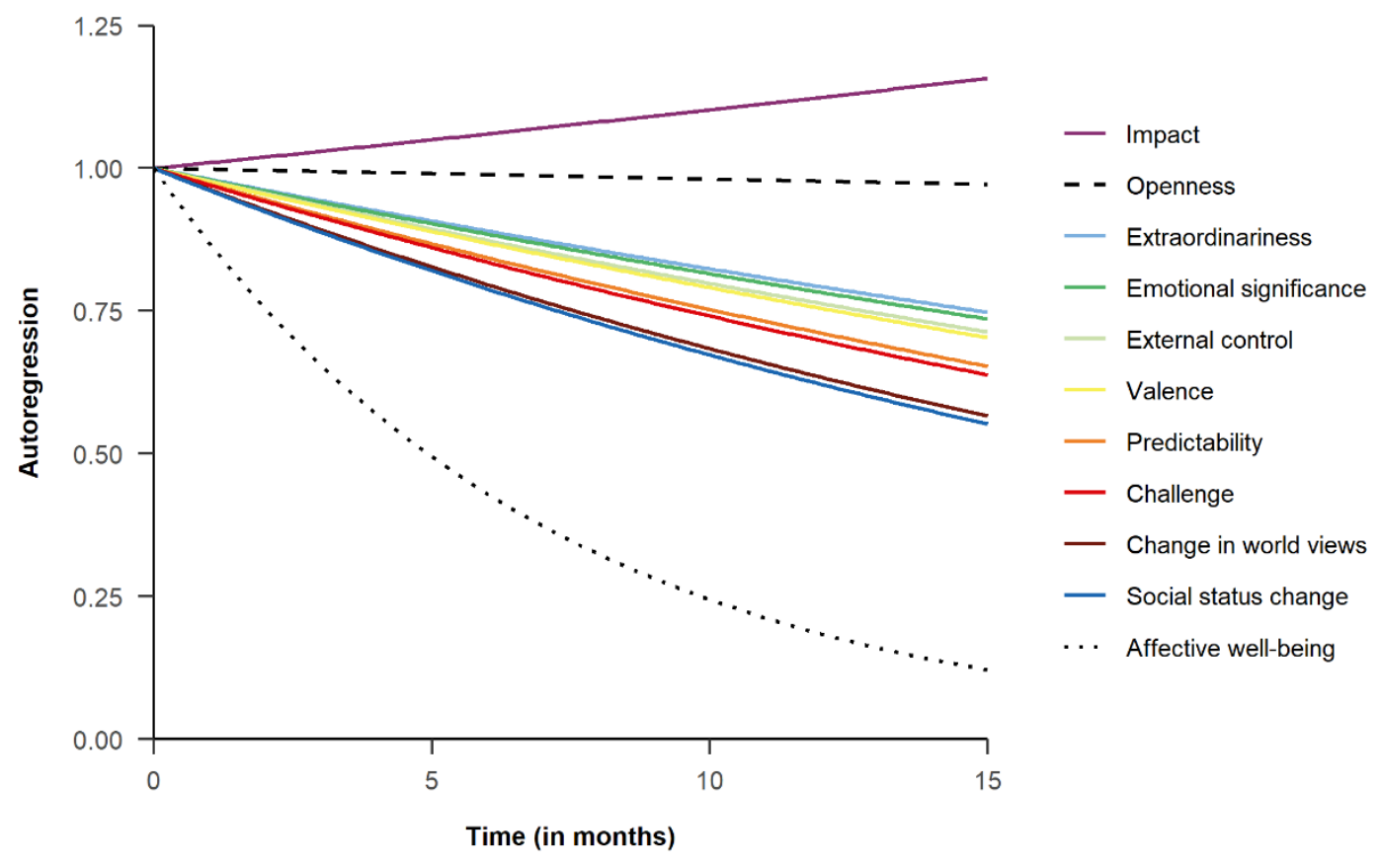

Note. Discrete time autoregressive coefficients for different lengths of the retest interval are depicted. The order of the constructs in the legend corresponds to their order in the graph (from high to low autoregressive coefficients). In the supplemental material, there is a depiction of autoregressive coefficients separately for each life event characteristic with openness and affective well-being as benchmarks for interpretation (Figure S3).

First, for the interpretation of the continuous time auto-effects, it is important to recall that they were expected to be negative with values closer to zero indicating a higher rank-order stability (Driver \& Voelkle, 2018a; Ryan et al., 2018). All life event characteristics except impact had negative continuous time auto-effects and their confidence intervals did not include zero. This means that the discrete time autoregressive coefficients significantly decreased with increasing length of the retest interval. Thus, results for all life event characteristics (except impact) were consistent with Hypothesis 1 . In contrast to the life event characteristics, openness, neuroticism, and extraversion did not reveal a statistically significant decrease within the time frame of the study, which means that they were highly stable over one year. 
Second, life event characteristics descriptively differed in their rank-order stability with extraordinariness having (beside impact, see below) the highest rank-order stability $(a=-0.019,95 \% \mathrm{CI}=[-0.032,-0.008])$ and social status change having the lowest rank-order stability $(a=-0.040,95 \% \mathrm{CI}=[-0.054,-0.026])$. However, the confidence intervals of the auto-effects overlapped for the different life event characteristics.

Third, autoregressive effects of the life event characteristics (except impact) were in between the autoregressive effects of openness and affective well-being. For a retest interval of one year, affective well-being had a discrete time autoregressive coefficient of $a_{12}^{*}=0.185$, autoregressive coefficients for the life event characteristics ranged from $a_{12}^{*}=0.622$ to $a_{12}^{*}=0.793$, and openness had an autoregressive coefficient of $a_{12}^{*}=0.977$. Thus, rank-order stabilities of the life event characteristics were in between the ones of affective well-being and the Big Five personality traits—-but being closer to the Big Five.

Fourth, there was an unexpected finding for the ECQ subscale impact. For impact, we found a small positive auto-effect $(a=0.010,95 \% \mathrm{CI}=[0.002,0.017])$ which indicates an "explosive process" that moves further and further away from an equilibrium position as the time interval increases (Driver \& Voelkle, 2018a). While an explosive process is unrealistic as a generating process over longer time frames, it can be an adequate characterization of the dynamics for the observed time frame (Driver \& Voelkle, 2018b). Within one year, the small positive auto-effect for impact might indicate a positive self-feedback (e.g., high impact ratings get somewhat higher over time, low ratings get somewhat lower). However, when using the four-item version for the subscale impact, the confidence interval of the auto-effect included zero $(a=0.006,95 \% \mathrm{CI}=[-0.002,0.015])$. A confidence interval including zero means that there is no significant change in discrete time autoregressive coefficients with increasing lengths of the retest interval, which in turn can be interpreted as high stability of the subscale impact. 


\section{Mean-Level Stability}

Mean-level stability measures the direction and extent of absolute changes in a given construct averaged over all participants. Our second research question was whether there are mean-level changes for the different life event characteristics. We hypothesized that extraordinariness decreases over time (Hypothesis 2) and that predictability (Hypothesis 3) and valence (Hypothesis 4) increase over time. To evaluate Research Question 2 and Hypothesis 2 to 4 , we computed effect sizes for mean-level change over an interval of 15 months $\left(E S_{15}\right)$, which can be interpreted in $S D$ units. We further compared two nested models: a restricted model not allowing any mean-level changes and an unrestricted model allowing mean-level changes. Consequently, if a model comparison is statistically significant, the results indicate a significant mean-level change for the respective construct. Table 4 summarizes the results of this computations. Mean-level changes of the latent processes over time are also depicted in Figure 4. In the following, the main findings of these analyses are summarized.

\section{Table 4}

Effect sizes for mean-level changes, results of model comparisons for models with and without stationary means, and intraclass correlations

\begin{tabular}{lccccc}
\hline & & \multicolumn{3}{c}{ Model comparison } & \\
\cline { 3 - 5 } & $\boldsymbol{E S}_{\mathbf{1 5}}$ & $\Delta-2 \mathrm{LL}(1)$ & $p$ & $\Delta \mathrm{AIC}$ & ICC \\
\hline Challenge & 0.06 & 1.10 & .294 & -0.90 & .80 \\
Change in world views & 0.41 & 28.19 & $<.001$ & 26.19 & .63 \\
Emotional significance & -0.15 & 5.10 & .024 & 3.10 & .83 \\
External control & 0.17 & 5.37 & .021 & 3.37 & .78 \\
Extraordinariness & -0.19 & 8.08 & .004 & 6.08 & .76 \\
Impact & -0.14 & 4.53 & .033 & 2.53 & .94 \\
Predictability & -0.08 & 2.19 & .139 & 0.19 & .85 \\
Social status change & -0.11 & 2.51 & .142 & 0.15 & .68 \\
Valence & 0.10 & 5.64 & .018 & 3.64 & .87 \\
Openness & $<0.01$ & $<0.01$ & .955 & -2.00 & .98 \\
Affective well-being & 0.07 & 0.64 & .423 & -1.36 & .53 \\
\hline
\end{tabular}

Note. $E S_{15}=$ effect size for mean-level changes over 15 months; $\Delta-2 \mathrm{LL}=$ change in -2 Log-Likelihood; $\Delta \mathrm{AIC}=$ change in Akaike's information criteria; ICC = intraclass correlation. 


\section{Figure 4}

\section{Mean-level changes over time}

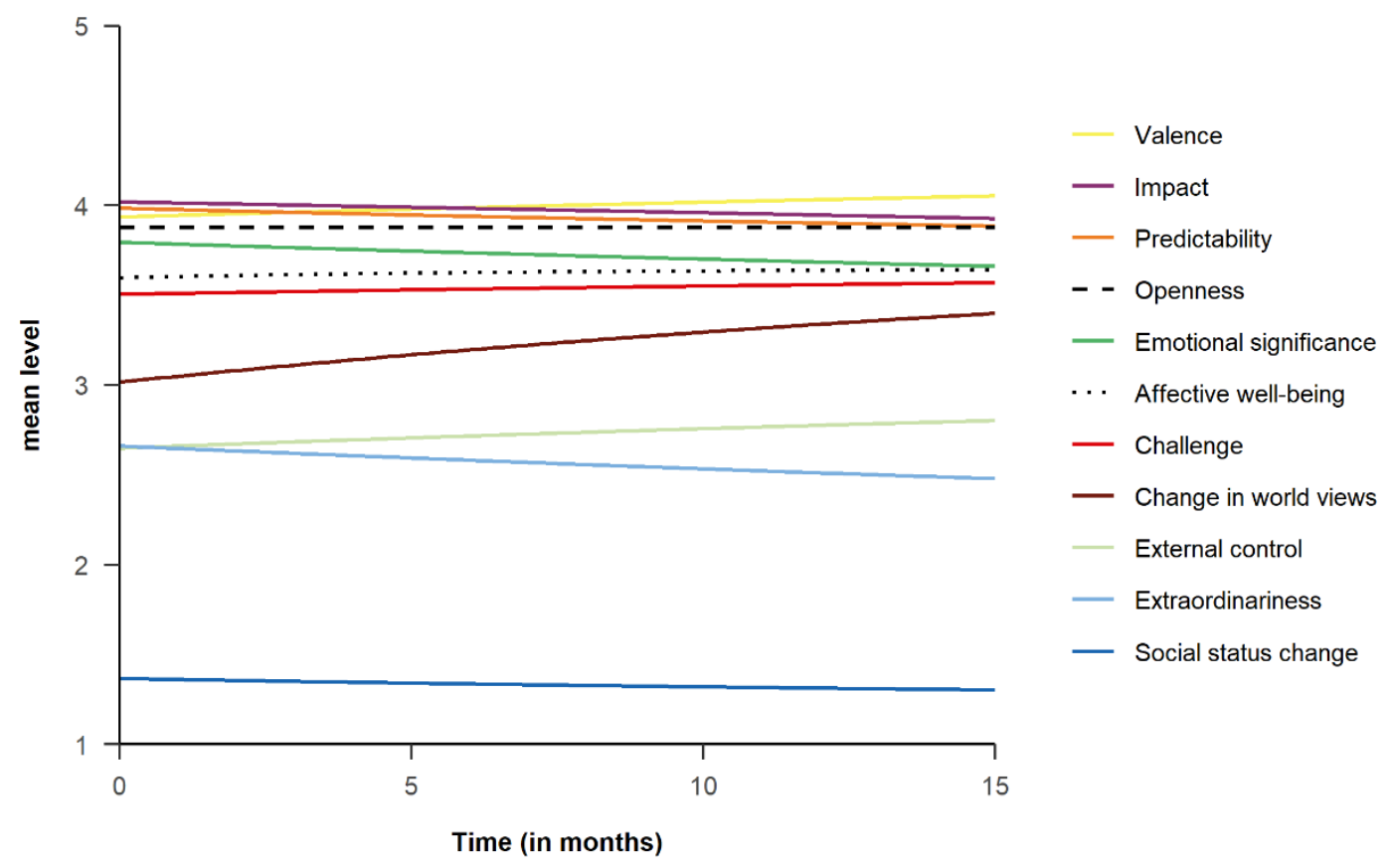

Note. Mean-level changes for all life event characteristics, affective well-being, and openness are depicted. The order of the constructs in the legend corresponds to their order in the graph (from high to low mean level at 15 months). Higher values indicate a higher level of the respective construct. In the supplemental material, there is a depiction of mean-level changes for each life event characteristic separately with openness and affective wellbeing as benchmarks for interpretation (Figure S4).

Effect sizes for mean-level changes for the life event characteristics ranged from 0.06 (challenge) to 0.41 (change in world views). Contrary to Hypothesis 3 (predictability increases over time) and Hypothesis 4 (valence increases over time), neither predictability $\left(E S_{15}=-0.08\right)$ nor valence $\left(E S_{15}=0.10\right)$ significantly changed. Similarly, challenge $\left(E S_{15}=0.06\right)$ and social status change $\left(E S_{15}=-0.11\right)$ showed only weak and non-significant mean-level changes (all $p s>.05$ and $\triangle \mathrm{AIC}<4)$. Impact $\left(E S_{15}=-0.14\right)$, emotional significance $\left(E S_{15}=-0.15\right)$, and external control $\left(E S_{15}=0.17\right)$ showed slightly stronger but still non-significant mean-level changes $(\triangle \mathrm{AIC}<4)$.

In contrast, there were significant mean-level changes for extraordinariness and change in world views. Consistent with Hypothesis 2, perceived extraordinariness of major life events 
decreased over time $\left(E S_{15}=-0.19, \Delta-2 \mathrm{LL}(1)=8.08, p=.004, \Delta \mathrm{AIC}=6.08\right)$, meaning that participants perceived their life event as less extraordinary with increasing time since the event. Change in world views $\left(E S_{15}=0.41, \Delta-2 \mathrm{LL}(1)=28.19, p<.001, \Delta \mathrm{AIC}=26.19\right)$ increased over time, indicating that participants perceived major life events as more world-view changing with increasing retest interval.

\section{Ratio of Between-Person and Within-Person Variance}

To evaluate Research Question 3 concerning the ratio of between-person and withinperson variance, we computed intraclass correlations. The results are presented in Table 4 . In general, intraclass correlations showed rather high values for all life event characteristics, openness, and affective well-being, indicating that most of the long-range variance can be attributed to between-person differences (e.g., $63 \%$ to $94 \%$ of the long-range variance of the life event characteristics can be attributed to between-person differences). In principle, we found a result pattern comparable to the one of the rank-order stabilities: The intraclass correlations for the life event characteristics were in between the ones of affective well-being $(\mathrm{ICC}=.53)$ and openness $(\mathrm{ICC}=.98)$ - but being on average somewhat closer to openness and the other Big Five. At the same time, the results for intraclass correlations and rank-order stability were not identical. For example, extraordinariness was the life event characteristic with the highest rank-order stability but had a relatively low intraclass correlation $(\mathrm{ICC}=.76)$ indicating that there were within-person fluctuations that did not result in changes in rankorders for this subscale. To sum up, between-person differences seemed to be most important for the life event characteristics impact $(\mathrm{ICC}=.94)$, valence $(\mathrm{ICC}=.87)$, and emotional significance $(\mathrm{ICC}=.83$ ); within-person variability was most important for the life event characteristics change in world views $(\mathrm{ICC}=.63)$ and social status change $(\mathrm{ICC}=.68)$.

\section{Discussion}

This longitudinal study used continuous time models (CTMs) to investigate how perceived event characteristics change over time. With multiple measurement occasions spread 
over one year, this study examined the stability and change of perceived event characteristics more comprehensively than previous studies (Ferguson et al., 1999; Frazier et al., 2011; Scherer \& Drumheller, 1992). We addressed three different research questions regarding their stability and change: First, we found the different life event characteristics to have a similar rank-order stability which decreased with increasing length of the retest interval. Moreover, perceived event characteristics were more rank-order stable than affective well-being but less rank-order stable than personality traits. Second, we found significant mean-level changes for the life event characteristics extraordinariness and change in world views: Over time, major life events were perceived as less extraordinary but as more world-view changing. Third, most of the (longrange) variance in life event characteristics was explained by between-person differences. In the following, we discuss explanations for and theoretical implications of these findings.

\section{Rank-Order Stability of Perceived Event Characteristics}

Compared to other psychological constructs, life event characteristics were moderately rank-order stable: Their rank-order stabilities were in between the ones of the Big Five personality traits and affective well-being, being somewhat closer to personality traits. This result seems theoretically reasonable: Personality traits are among the most stable constructs in psychology and affective well-being has a considerably lower stability (Anusic \& Schimmack, 2016). Compared the results by de Moor et al. (2021) who used CTMs to examine the rankorder stability and interplay of self-esteem and relationship satisfaction, the life event characteristics were approximately as stable as self-esteem but less stable than relationship satisfaction. Thus, our findings contradict the criticism that perceived event characteristics are strongly biased by the current emotional state of a person (Hammen, 2005). If this criticism had been true, the rank-order stabilities of the life event characteristics would have been significantly lower. Nonetheless it is true that participants did change in their relative position within the sample, and that rank-order stabilities of almost all life event characteristics decreased with increasing length of the retest interval. 
Surprisingly, we did not find the expected mean-reverting process and decrease of rankorder stability with increasing length of the retest interval for the life event characteristic impact. For this subscale, a positive continuous time auto-effect was found. This finding might indicate a kind of positive self-feedback within one year (e.g., those who rate impact low initially rate it even lower over time). However, this feedback effect was rather small, and in our robustness check, the continuous time auto-effect did not significantly deviate from zero. This finding might indicate a very high rank-order stability of this life event characteristic over longer retest intervals which should be investigated in future research. If this interpretation holds, one will have to explain why impact is more rank-order stable than the other life event characteristics. It might be the case that impact is a central property of major life events that therefore shows little change in rank orders.

\section{Mean-Level Stability of Perceived Event Characteristics}

The life event characteristics differed in their mean-level stability. For most life event characteristics, no significant mean-level changes over time were found. However, for extraordinariness and change in world views, there were significant mean-level changes such that perceived extraordinariness decreased and that perceived change in world-views increased over time. This finding is in line with the results by Kritzler et al. (2021) who found that perceived event characteristics were correlated with the temporal distance between the occurrence and the rating of a major life event. Consequently, for future research, the time lag between the occurrence and rating of a major life event should be considered in the interpretation of findings.

Regarding the effect sizes of the mean-level changes, Funder and Ozer (2019) proposed new guidelines for the interpretation of effect sizes in psychological research that move beyond the ones by Cohen (1988). Their guidelines are based on the average effect size in the published literature and other effect sizes that are relevant in daily experiences. According to Funder and Ozer (2019), the effect sizes for the mean-level changes of extraordinariness and change in 
world views are small (to medium at most). However, as they also suggest that effect sizes should be evaluated within context, it should be noted that the effect sizes for the mean-level changes of the life event characteristics were two to four times larger than the effect sizes we found for the Big Five personality traits and affective well-being.

For extraordinariness, we found the hypothesized mean-level decrease over time. This finding is consistent with affective adaptation theory (Wilson \& Gilbert, 2008) which states that an event is perceived as less extraordinary over time because explanations for the occurrence of the major life event are found. However, this finding might also be due to a kind of selection effect. The What's Next? Study was primarily addressed to young adults who had just finished school. As a result of the transition to university, new peer relations are established and peer groups are more homogenous than peer groups at high school (good grades, accepted at university, similar interests because they study the same career). Thus, their new peer group may also have experienced similar major life events, so that one's own major life event seems less extraordinary.

We did not find the hypothesized mean-level changes for predictability and valence. These hypotheses had been based on literature on hindsight bias and positive memory bias. As noted above, these biases are usually assessed by comparing pre- and post-event ratings and only few studies focused on their unfolding over time (Blank et al., 2008; Bryant \& Brockway, 1997; Bryant \& Guilbault, 2002). In their study on hindsight bias, Blank et al. (2008) identified different components of the phenomenon and hypothesized that the sense of predictability increases over time. However, post-event measurements were only taken in the first month after the event. It could be that the increase in the feeling of predictability is limited to the early postevent period. Thus, we might not have found any mean-level changes because this process had already been completed at our first measurement occasion (T1 took place on average seven weeks after the major life event occurred). 
The strongest mean-level change was found for change in world views. The finding that major life events are perceived as more world-view changing over time might indicate that the relevance of a major life event for one's own world view is only becoming clear over time (Jayawickreme \& Blackie, 2014; Park, 2010). However, it should be noted that we had no a priori hypotheses about mean-level changes in changes in world views. Thus, this result is exploratory and should be replicated in future research.

\section{Ratio of Between-Person and Within-Person Variance}

We found that most of the long-range variance of the life event characteristics can be attributed to between-person differences. However, these interindividual differences are based on two sources. On the one hand, the participants experienced and rated different major life events, which obviously contributes to interindividual differences. On the other hand, trait-like individual differences in the perception of major life events might also exist (e.g., stable tendencies of people to perceive major life events as positive, predictable, or extraordinary). For example, Power and Hill (2010) found consistent individual differences in the ratings of hypothetical minor life events, which were correlated with different personality traits (see also Rakhshani et al., 2020). Future research should attempt to separate these two sources of between-person variance in context of perceptions of major life events as well.

\section{Theoretical Implications}

Our results have implications for existing appraisal theories as well as claims about episodic memory of major life events. First, our results at least partly challenge the importance of reappraisal processes. In the appraisal theory by Lazarus and Folkman (1984), reappraisal is described as one way of cognitive coping with stressful situations and it is also conceptualized as an important emotion-regulation strategy (Ford \& Troy, 2019; Gross, 2002; Uusberg et al., 2019). In our study, however, most event characteristics had high rank-order and mean-level stabilities. These stabilities were particularly high for perceived valence and emotional significance, the two event characteristics that are conceptually most similar to the emotional 
processes associated with reappraisal. Consequently, reappraisal as way of coping and emotion regulation may have occurred only to a small extent in our sample.

Second, our results for the life event characteristic change in world views are in line with the meaning-making literature. The meaning-making model by Park (2010) assumes that successful meaning making processes of major life events may change one's global meaning (i.e., individuals' general orienting systems beliefs, goals, and feelings). The ECQ subscale change in world views (e.g., viewing things from a different perspective, changing attitudes due to the event) is conceptually similar to this change in global meaning. Consequently, our finding that life events are perceived as increasingly world-view changing over time is consitent with the notion that the process of meaning making includes changes of the global meaning. Furthermore, our results add some insight into the time course of the meaning-making process. Park (2010) noted that "meaning making is typically described as occurring over time [...], but the time frame has not been clearly specified" (p. 290). The mean-level increase of change in world views found in our study indicates that the process of meaning making occurs over a time frame of at least one year. For future research, it would be interesting to investigate whether this mean-level increase in change in world views continues over even longer time frames and whether it is associated with a better long-term adjustment to the event (e.g., reduced distress) as predicted by Park's (2010) meaning-making model.

Third, our results allow to draw some conclusions regarding episodic memory and memory biases of major life events. As outlined above, our hypotheses regarding hindsight bias and positive memory bias were not supported. Instead, our results suggest that these biases are limited in time and that they might act on a short time scale (Bryant \& DeHoek, 2006). Regarding the memory of emotions, it should be noted that the subscale emotional significance was among the ones with the highest rank-order stabilities and intraclass correlations and that it did not show a significant mean-level change. These results speak against strong distortions of memory of emotions due to post-event knowledge or personality (Levine, 1997; Safer et al., 
2016). On a more general level, the high stability of the life event characteristics might imply that episodic memory of major life events is in general quite accurate over time. Our results thus add to recent findings that real-life events are stored in episodic memory more accurately than initially expected (Diamond et al., 2020).

Fourth, our results also provide insights into the "nature" of the event perceptions themselves. In general, event perceptions were quite stable over one year, so they might be useful predictors of changes after major life events even if they were assessed only once (Luhmann et al., 2020). At the same time, it is also true that there were changes in the perceived event characteristics. One reason for such changes might be that the consequences of major life events actually change over time (e.g., Sheldon \& Lyubomirsky, 2012). For example, two people who have just started a new job may both consider the social status change caused by this job to be relatively high. After some time, one person quits the job and therefore estimates the social status change of the job lower than initially. The other person gets promoted on this job and thus rates the social status change higher than initially. Additionally, the fact that the change-related life event characteristics, social status change and change in world views, had the lowest intraclass correlations further supports the argument that changes in real-life consequences of major life events may cause changes in the perceived event characteristics. Another reason for changes in event perceptions might be that the evaluation standard for rating major life events might change over time. For example, new positive life events could cause an increase in person's aspiration level, causing the previous life event to be perceived as less positive (Sheldon et al., 2013).

We can only speculate about the reasons for such changes here, so future research should explicitly investigate possible factors contributing to changes in perceptions of major life events (e.g., by using experimental designs). Moreover, it would be interesting to have a closer look at those individuals who show the most pronounced changes in event perceptions. Building on theories of post-traumatic growth (Jayawickreme \& Blackie, 2014), one might suspect that 
these individuals also exhibit the most extensive changes in subjective well-being or personality traits following major life events. In this context, future research should also investigate the interplay of perceived event characteristics and subjective well-being over time. For this purpose, CTMs (including cross-effects) might again be an adequate analytical method.

\section{Limitations and Future Directions}

This study had several limitations. First, we used a non-representative, highly educated, predominantly female sample of young adults for our analyses. This sample might differ from other populations in the occurrence and perceptions of major life events. Possibly, the results for stability and change of the life event characteristics are also at least partly influenced by these sample characteristics. For example, our young and highly educated participants mainly named positive life events at T1 such as graduating from high school, meeting new people, and starting college. Consequently, the average valence rating at $\mathrm{T} 1$ was already very positive, which might be a reason for why no significant increase in valence over time was found.

Second, some results of the present paper should be regarded as preliminary. As noted above, the meaning and robustness of the positive autoregressive drift coefficient of the life event characteristic impact should be investigated in future research. The same applies to the finding on the significant mean-level change for change in world views. Moreover, our modeling approach to detect mean-level changes was adequate to answer the question whether there are overall mean-level changes in the data, but it was not adequate to detect every possible kind of mean-level change (e.g., oscillations; Driver \& Voelkle, 2018b).

Third, this paper focused on describing changes in event perceptions, but we did not explain them. Furthermore, this study did not directly address the question whether changes in the perceptions of major life events are correlated with changes in psychological outcomes such as mental health, subjective well-being, or personality. As outlined above, future research should continue here and investigate factors contributing to the stability and change of event 
perceptions as well as the interplay of changes in event perceptions with changes in mental health, subjective well-being, or personality.

\section{Conclusion}

This study systematically examined changes in the perceived characteristics of major life events. We found that the rank orders of these perceptions were relatively stable, that there were significant mean-level changes in two life event characteristics, and that most of the variance in life event characteristics was explained by between-person differences. The contribution of this study is threefold: First, the consideration of perceived event characteristics is an important line of research to disambiguate diverging findings on the effects of major life events on different psychological outcomes (Luhmann et al., 2020). Investigating the stability of these perceptions over time is an important cornerstone to better understand the construct of perceived event characteristics, and it shows the relevance of considering the temporal dimension when studying (perceptions of) major life events. Second, our findings have implications for theories on appraisal and meaning making. The mean-level increase of change in world views and the mean-level decrease of extraordinariness are consistent with the meaning-making model (Park, 2010) and affective adaptation theory (Wilson \& Gilbert, 2008). However, the rather high stabilities of the life event characteristics valence and emotional significance challenge the importance of reappraisal processes of major life events in our sample. Third, CTMs are a promising methodological tool to investigate the dynamics of psychological processes (Voelkle et al., 2018). This study demonstrated their use to examine stability and change of psychological constructs. 


\section{References}

Adler, O., \& Pansky, A. (2020). A "rosy view" of the past: Positive memory biases. In T. Aue \& H. Okon-Singer (Eds.), Cognitive biases in health and psychiatric disorders (pp. 139171). Elsevier. https://doi.org/10.1016/B978-0-12-816660-4.00007-6

Andreassen, C. S. (2016). A longitudinal study of the relationship between the five-factor model of personality and workaholism. TPM - Testing, Psychometrics, Methodology in Applied Psychology, 23(3), 285-298. https://doi.org/10.4473/TPM23.3.2

Anusic, I., \& Schimmack, U. (2016). Stability and change of personality traits, self-esteem, and well-being: Introducing the meta-analytic stability and change model of retest correlations. Journal of Personality and Social Psychology, 110(5), 766-781. https://doi.org/10.1037/pspp0000066

Arsenian, S. (1970). Change in evaluative attitudes during twenty-five years. The Journal of Applied Psychology, 54(4), 302-304. https://doi.org/10.1037/h0029673

Assari, S., \& Lankarani, M. M. (2016). Association between stressful life events and depression: Intersection of race and gender. Journal of Racial and Ethnic Health Disparities, 3(2), 349-356. https://doi.org/10.1007/s40615-015-0160-5

Beards, S., Gayer-Anderson, C., Borges, S., Dewey, M. E., Fisher, H. L., \& Morgan, C. (2013). Life events and psychosis: A review and meta-analysis. Schizophrenia Bulletin, 39(4), 740-747. https://doi.org/10.1093/schbul/sbt065

Berenbaum, H., Thompson, R. J., Milanek, M. E., Boden, M. T., \& Bredemeier, K. (2008). Psychological trauma and schizotypal personality disorder. Journal of Abnormal Psychology, 117(3), 502-519. https://doi.org/10.1037/0021-843X.117.3.502

Blank, H., Nestler, S., Collani, G. von, \& Fischer, V. (2008). How many hindsight biases are there? Cognition, 106(3), 1408-1440. https://doi.org/10.1016/j.cognition.2007.07.007 
Bleidorn, W., \& Hopwood, C. J. (2019). Stability and change in personality traits over the lifespan. In D. P. McAdams, R. L. Shiner, \& J. L. Tackett (Eds.), Handbook of personality development (pp. 237-252).

Bleidorn, W., Hopwood, C. J., \& Lucas, R. E. (2018). Life events and personality trait change. Journal of Personality, 86(1), 83-96. https://doi.org/10.1111/jopy.12286

Bleidorn, W., Kandler, C., Riemann, R., Spinath, F. M., \& Angleitner, A. (2009). Patterns and sources of adult personality development: Growth curve analyses of the NEO PI-R scales in a longitudinal twin study. Journal of Personality and Social Psychology, 97(1), 142155. https://doi.org/10.1037/a0015434

Borghuis, J., Denissen, J. J. A., Oberski, D., Sijtsma, K., Meeus, W. H. J., Branje, S., Koot, H. M., \& Bleidorn, W. (2017). Big Five personality stability, change, and codevelopment across adolescence and early adulthood. Journal of Personality and Social Psychology, 113(4), 641-657. https://doi.org/10.1037/pspp0000138

Brose, A., Blanke, E. S., Schmiedek, F., Kramer, A. C., Schmidt, A., \& Neubauer, A. B. (2020). Change in mental health symptoms during the COVID-19 pandemic: The role of appraisals and daily life experiences. Journal of Personality. Advance online publication. https://doi.org/10.1111/jopy.12592

Brugha, T., Bebbington, P., Tennant, C., \& Hurry, J. (1985). The List of Threatening Experiences: A subset of 12 life event categories with considerable long-term contextual threat. Psychological Medicine, 15(1), 189-194. https://doi.org/10.1017/S003329170002105X

Bryant, F. B., \& Brockway, J. H. (1997). Hindsight bias in reaction to the verdict in the O. J. Simpson criminal trial. Basic and Applied Social Psychology, 19(2), 225-241. https://doi.org/10.1207/15324839751037075 
Bryant, F. B., \& DeHoek, A. (2006). Looking back on what we knew and when we knew it: The role of time in the development of hindsight bias. In L. J. Sanna \& E. C.-H. Chang (Eds.), Judgments over time: The interplay of thoughts, feelings, and behaviors (pp. 230250). Oxford University Press. https://doi.org/10.1093/acprof:oso/9780195177664.003.0013

Bryant, F. B., \& Guilbault, R. L. (2002). "I knew it all along" eventually: The development of hindsight bias in reaction to the Clinton impeachment verdict. Basic and Applied Social Psychology, 24(1), 27-41. https://doi.org/10.1207/153248302753438903

Caspi, A., Roberts, B. W., \& Shiner, R. L. (2005). Personality development: Stability and change. Annual Review of Psychology, 56, 453-484. https://doi.org/10.1146/annurev.psych.55.090902.141913

Chung, J. M., Robins, R. W., Trzesniewski, K. H., Noftle, E. E., Roberts, B. W., \& Widaman, K. F. (2014). Continuity and change in self-esteem during emerging adulthood. Journal of Personality and Social Psychology, 106(3), 469-483. https://doi.org/10.1037/a0035135

Cicchetti, D. V. (1994). Guidelines, criteria, and rules of thumb for evaluating normed and standardized assessment instruments in psychology. Psychological Assessment, 6(4), 284 290. https://doi.org/10.1037/1040-3590.6.4.284

Cohen, J. (1988). Statistical Power Analysis for the Behavioral Sciences (2nd ed.). Taylor and Francis. http://gbv.eblib.com/patron/FullRecord.aspx?p=1192162

Costa, P. T., Herbst, J. H., McCrae, R. R., \& Siegler, I. C. (2000). Personality at midlife: Stability, intrinsic maturation, and response to life events. Assessment, 7(4), 365-378. https://doi.org/10.1177/107319110000700405 
Crawford, D. W., Godbey, G., \& Crouter, A. C. (1986). The stability of leisure preferences. Journal of Leisure Research, 18(2), 96-115. https://doi.org/10.1080/00222216.1986.11969649

Damian, R. I., Spengler, M., Sutu, A., \& Roberts, B. W. (2019). Sixteen going on sixty-six: A longitudinal study of personality stability and change across 50 years. Journal of Personality and Social Psychology, 117(3), 674-695. https://doi.org/10.1037/pspp0000210

de Moor, E. L., Denissen, J. J. A., Emons, W. H. M., Bleidorn, W., Luhmann, M., Orth, U., \& Chung, J. M. (2021). Self-esteem and satisfaction with social relationships across time. Journal of Personality and Social Psychology, 120(1), 173-191. https://doi.org/10.1037/pspp0000379

Deboeck, P. R. (2013). Dynamical systems and models of continuous time. In T. D. Little (Ed.), The oxford handbook of quantitative methods: Statistical Analysis (2nd ed., pp. 411431). Oxford University Press USA.

Diamond, N. B., Armson, M. J., \& Levine, B. (2020). The truth is out there: Accuracy in recall of verifiable real-world events. Psychological Science, 095679762095481. https://doi.org/10.1177/0956797620954812

Diener, E., Lucas, R. E., \& Scollon, C. N. (2006). Beyond the hedonic treadmill: Revising the adaptation theory of well-being. The American Psychologist, 61(4), 305-314. https://doi.org/10.1037/0003-066X.61.4.305

Diener, E., Wirtz, D., Tov, W., Kim-Prieto, C., Choi, D., Oishi, S., \& Biswas-Diener, R. (2010). New well-being measures: Short scales to assess flourishing and positive and negative feelings. Social Indicators Research, 97(2), 143-156. https://doi.org/10.1007/s11205-009-9493-y 
Dohrenwend, B. S., Krasnoff, L., Askenasy, A. R., \& Dohrenwend, B. P. (1978). Exemplification of a method for scaling life events: The Peri Life Events Scale. Journal of Health and Social Behavior, 19(2), 205-229.

Dohrenwend, B. P. (2006). Inventorying stressful life events as risk factors for psychopathology: Toward resolution of the problem of intracategory variability. Psychological Bulletin, 132(3), 477-495. https://doi.org/10.1037/0033-2909.132.3.477

Dormann, C., \& Griffin, M. A. (2015). Optimal time lags in panel studies. Psychological Methods, 20(4), 489-505. https://doi.org/10.1037/met0000041

Driver, C. (2020). Latent growth curves, state dependent error. https://cdriver.netlify.app/post/lgc/

Driver, C., Oud, J. H. L., \& Voelkle, M. C. (2017). Continuous time structural equation modeling with R package ctsem. Journal of Statistical Software, 77(5). https://doi.org/10.18637/jss.v077.i05

Driver, C., \& Voelkle, M. C. (2018a). Hierarchical Bayesian continuous time dynamic modeling. Psychological Methods, 23(4), 774-799. https://doi.org/10.1037/met0000168

Driver, C., \& Voelkle, M. C. (2018b). Understanding the time course of interventions with continuous time dynamic models. In K. van Montfort, J. H. L. Oud, \& M. C. Voelkle (Eds.), Continuous time modeling in the behavioral and related sciences (pp. 79-109). Springer International Publishing.

Fassbender, I., Haehner, P., Buecker, S., \& Luhmann, M. (2021). Changes in prosocialness and empathy associated with characteristics of major life events [Manuscript submitted for publication].

Fassbender, I., \& Luhmann, M. (2021). A German Adaptation and a Short Form of the Prosocialness Scale [Manuscript submitted for publication]. 
Ferguson, E., Matthews, G., \& Cox, T. (1999). The Appraisal of Life Events (ALE) scale: Reliability and validity. British Journal of Health Psychology, 4(2), 97-116. https://doi.org/10.1348/135910799168506

Fessel, F., Epstude, K., \& Roese, N. J. (2009). Hindsight bias redefined: It's about time. Organizational Behavior and Human Decision Processes, 110(1), 56-64. https://doi.org/10.1016/j.obhdp.2009.07.001

Fischhoff, B., \& Beyth, R. (1975). I knew it would happen. Organizational Behavior and Human Performance, 13(1), 1-16. https://doi.org/10.1016/0030-5073(75)90002-1

Ford, B. Q., \& Troy, A. S. (2019). Reappraisal reconsidered: A closer look at the costs of an acclaimed emotion-regulation strategy. Current Directions in Psychological Science, 28(2), 195-203. https://doi.org/10.1177/0963721419827526

Fraley, R. C., \& Roberts, B. W. (2005). Patterns of continuity: A dynamic model for conceptualizing the stability of individual differences in psychological constructs across the life course. Psychological Review, 112(1), 60-74. https://doi.org/10.1037/0033295X.112.1.60

Frazier, P., Keenan, N., Anders, S., Perera, S., Shallcross, S., \& Hintz, S. (2011). Perceived past, present, and future control and adjustment to stressful life events. Journal of Personality and Social Psychology, 100(4), 749-765. https://doi.org/10.1037/a0022405

Funder, D. C., \& Ozer, D. J. (2019). Evaluating effect size in psychological research: Sense and nonsense. Advances in Methods and Practices in Psychological Science, 2(2), 156168. https://doi.org/10.1177/2515245919847202

Gow, A. J., Johnson, W., Pattie, A., Brett, C. E., Roberts, B., Starr, J. M., \& Deary, I. J. (2011). Stability and change in intelligence from age 11 to ages 70,79 , and 87 : The Lothian Birth Cohorts of 1921 and 1936. Psychology and Aging, 26(1), 232-240. https://doi.org/10.1037/a0021072 
Gross, J. J. (2002). Emotion regulation: Affective, cognitive, and social consequences. Psychophysiology, 39(3), 281-291. https://doi.org/10.1017/S0048577201393198

Gustavsson, J. P., Weinryb, R. M., Göransson, S., Pedersen, N. L., \& Åsberg, M. (1997). Stability and predictive ability of personality traits across 9 years. Personality and Individual Differences, 22(6), 783-791. https://doi.org/10.1016/S0191-8869(96)00268-1

Hamaker, E. L., \& Grasman, R. P. P. P. (2014). To center or not to center? Investigating inertia with a multilevel autoregressive model. Frontiers in Psychology, 5, 1492. https://doi.org/10.3389/fpsyg.2014.01492

Hammen, C. (2005). Stress and depression. Annual Review of Clinical Psychology, 1, 293319. https://doi.org/10.1146/annurev.clinpsy.1.102803.143938

Hasan, N., \& Power, T. G. (2004). Children's appraisal of major life events. The American Journal of Orthopsychiatry, 74(1), 26-32. https://doi.org/10.1037/0002-9432.74.1.26

Hawkins, S. A., \& Hastie, R. (1990). Hindsight: Biased judgments of past events after the outcomes are known. Psychological Bulletin, 107(3), 311-327. https://doi.org/10.1037/0033-2909.107.3.311

Headey, B., \& Wearing, A. (1989). Personality, life events, and subjective well-being: Toward a dynamic equilibrium model. Journal of Personality and Social Psychology, 57(4), 731-739. https://doi.org/10.1037/0022-3514.57.4.731

Hecht, M., \& Voelkle, M. C. (2021). Continuous-time modeling in prevention research: An illustration. International Journal of Behavioral Development, 45(1), 19-27. https://doi.org/10.1177/0165025419885026

Hecht, M., \& Zitzmann, S. (2020). Sample size recommendations for continuous-time models: Compensating shorter time series with larger numbers of persons and vice versa. Structural Equation Modeling: A Multidisciplinary Journal, 17, 1-8. https://doi.org/10.1080/10705511.2020.1779069 
Holmes, T. H., \& Rahe, R. H. (1967). The social readjustment rating scale. Journal of Psychosomatic Research, 11(2), 213-218. https://doi.org/10.1016/0022-3999(67)90010-4

Jayawickreme, E., \& Blackie, L. E. R. (2014). Post-traumatic growth as positive personality change: Evidence, controversies and future directions. European Journal of Personality, 28(4), 312-331. https://doi.org/10.1002/PER.1963

Jorgensen, T. D., Pornprasertmanit, S., Schoemann, A. M., \& Rosseel, Y. (2020). semTools: Useful tools for structural equation modeling. https://CRAN.Rproject.org/package $=$ semTools

Kendler, K. S., Hettema, J. M., Butera, F., Gardner, C. O., \& Prescott, C. A. (2003). Life event dimensions of loss, humiliation, entrapment, and danger in the prediction of onsets of major depression and generalized anxiety. Archives of General Psychiatry, 60(8), 789-796. https://doi.org/10.1001/archpsyc.60.8.789

Kritzler, S., Rakhshani, A., Terwiel, S., Fassbender, I., Donnellan, M. B., Lucas, R. E., \& Luhmann, M. (2021). Perceptions of major life events: Exploring typical event profiles, variability, and differences between raters. PsyArXiv. https://doi.org/10.31234/osf.io/fncz3

Kuiper, R. M., \& Ryan, O. (2018). Drawing conclusions from cross-lagged relationships: Reconsidering the role of the time-interval. Structural Equation Modeling: A Multidisciplinary Journal, 25(5), 809-823. https://doi.org/10.1080/10705511.2018.1431046

Lazarus, R. S., \& Folkman, S. (1984). Stress, appraisal, and coping. Springer. http://site.ebrary.com/lib/alltitles/docDetail.action?docID=10265641

Levine, L. J. (1997). Reconstructing memory for emotions. Journal of Experimental Psychology: General, 126(2), 165-177. https://doi.org/10.1037/0096-3445.126.2.165 
Lewinsohn, P. M., Mermelstein, R. M., Alexander, C., \& MacPhillamy, D. J. (1985). The Unpleasant Events Schedule: A scale for the measurement of aversive events. Journal of Clinical Psychology, 41(4), 483-498. https://doi.org/10.1002/10974679(198507)41:4<483::aid-jclp2270410407>3.0.co;2-0

Little, T. D. (2013a). Longitudinal structural equation modeling. Methodology in the social sciences. Guilford Press. http://gbv.eblib.com/patron/FullRecord.aspx?p=1137447

Little, T. D. (Ed.). (2013b). The oxford handbook of quantitative methods: Statistical Analysis (2nd ed.). Oxford University Press USA. http://search.ebscohost.com/login.aspx?direct=true \&scope=site $\& d b=$ lebk \&db=nlabk\&A $\mathrm{N}=603942$

Lucas, R. E. (2007). Adaptation and the set-point model of subjective well-being. Current Directions in Psychological Science, 16(2), 75-79. https://doi.org/10.1111/J.14678721.2007.00479.X

Lüdtke, O., Roberts, B. W., Trautwein, U., \& Nagy, G. (2011). A random walk down university avenue: Life paths, life events, and personality trait change at the transition to university life. Journal of Personality and Social Psychology, 101(3), 620-637. https://doi.org/10.1037/a0023743

Luhmann, M., Fassbender, I., Alcock, M., \& Haehner, P. (2020). A dimensional taxonomy of perceived characteristics of major life events. Journal of Personality and Social Psychology. Advance online publication. https://doi.org/10.1037/pspp0000291

Luhmann, M., Hofmann, W., Eid, M., \& Lucas, R. E. (2012). Subjective well-being and adaptation to life events: A meta-analysis. Journal of Personality and Social Psychology, 102(3), 592-615. https://doi.org/10.1037/a0025948 
Luhmann, M., \& Intelisano, S. (2018). Hedonic adaptation and the set point for subjective well-being. In E. Diener, S. Oishi, \& L. Tay (Eds.), Handbook of well-being. DEF Publishers.

Mancini, A. D., Bonanno, G. A., \& Clark, A. E. (2011). Stepping off the hedonic treadmill. Journal of Individual Differences, 32(3), 144-152. https://doi.org/10.1027/16140001/A000047

Meade, A. W., \& Craig, S. B. (2012). Identifying careless responses in survey data. Psychological Methods, 17(3), 437-455. https://doi.org/10.1037/a0028085

Merz, E. L., \& Roesch, S. C. (2011). Modeling trait and state variation using multilevel factor analysis with PANAS daily diary data. Journal of Research in Personality, 45(1), 2-9. https://doi.org/10.1016/j.jrp.2010.11.003

Mitchell, Thompson, Peterson, \& Cronk (1997). Temporal adjustments in the evaluation of events: The "Rosy View". Journal of Experimental Social Psychology, 33(4), 421-448. https://doi.org/10.1006/jesp.1997.1333

Mueller, S., Wagner, J., Smith, J., Voelkle, M. C., \& Gerstorf, D. (2018). The interplay of personality and functional health in old and very old age: Dynamic within-person interrelations across up to 13 years. Journal of Personality and Social Psychology, 115(6), 1127-1147. https://doi.org/10.1037/pspp0000173

Nakai, Y., Inoue, T., Toda, H., Toyomaki, A., Nakato, Y., Nakagawa, S., Kitaichi, Y., Kameyama, R., Hayashishita, Y., Wakatsuki, Y., Oba, K., Tanabe, H., \& Kusumi, I. (2014). The influence of childhood abuse, adult stressful life events and temperaments on depressive symptoms in the nonclinical general adult population. Journal of Affective Disorders, 158, 101-107. https://doi.org/10.1016/j.jad.2014.02.004

Olson, J. M., \& Zanna, M. P. (Eds.). (2013). Advances in experimental social psychology. Elsevier Science. 
Ormel, J., VonKorff, M., Jeronimus, B. F., \& Riese, H. (2017). Set-Point Theory and personality development: Reconciliation of a paradox. In J. Specht (Ed.), Personality development across the lifespan (pp. 117-137). Academic Press.

Park, C. L. (2010). Making sense of the meaning literature: An integrative review of meaning making and its effects on adjustment to stressful life events. Psychological Bulletin, 136(2), 257-301. https://doi.org/10.1037/A0018301

Paykel, E. S. (2003). Life events and affective disorders. Acta Psychiatrica Scandinavica, 108, 61-66. https://doi.org/10.1034/j.1600-0447.108.s418.13.x

Power, T. G., \& Hill, L. G. (2010). Individual differences in appraisal of minor, potentially stressful events: A cluster analytic approach. Cognition \& Emotion, 24(7), 1081-1094. https://doi.org/10.1080/02699930903122463

Putnick, D. L., \& Bornstein, M. H. (2016). Measurement invariance conventions and reporting: The state of the art and future directions for psychological research. Developmental Review, 41, 71-90. https://doi.org/10.1016/j.dr.2016.06.004

Rahm, T., Heise, E., \& Schuldt, M. (2017). Measuring the frequency of emotions-validation of the Scale of Positive and Negative Experience (SPANE) in Germany. PloS One, 12(2), e0171288. https://doi.org/10.1371/journal.pone.0171288

Rakhshani, A., Lucas, R. E., Donnellan, B., Fassbender, I., \& Luhmann, M. (2020). Personality and perceptions of major life events: Implications for personality development. PsyArXiv. https://doi.org/10.31234/osf.io/426g5

Rammstedt, B., Danner, D., Soto, C. J., \& John, O. P. (2018). Validation of the short and extra-short forms of the Big Five Inventory-2 (BFI-2) and their German adaptations. European Journal of Psychological Assessment, 36(1), 149-161. https://doi.org/10.1027/1015-5759/a000481 
Redfield, J., \& Stone, A. A. (1979). Individual viewpoints of stressful life events. Journal of Consulting and Clinical Psychology, 47(1), 147-154. https://doi.org/10.1037/0022006X.47.1.147

Roberts, B. W., \& DelVecchio, W. F. (2000). The rank-order consistency of personality traits from childhood to old age: A quantitative review of longitudinal studies. Psychological Bulletin, 126(1), 3-25. https://doi.org/10.1037//0033-2909.126.1.3

Roberts, B. W., Walton, K. E., \& Viechtbauer, W. (2006). Patterns of mean-level change in personality traits across the life course: A meta-analysis of longitudinal studies. Psychological Bulletin, 132(1), 1-25. https://doi.org/10.1037/0033-2909.132.1.1

Röseler, L., Wolf, D., Leder, J., \& Schütz, A. (2020). Test-retest reliability is not a measure of reliability or stability: A Friendly Reminder. PsyArXiv. https://doi.org/10.31234/OSF.IO/MT49R

Rosseel, Y. (2012). lavaan: An R package for structural equation modeling. Journal of Statistical Software, 48(2). https://doi.org/10.18637/jss.v048.i02

Ryan, O., Kuiper, R. M., \& Hamaker, E. L. (2018). A continuous-time Approach to intensive longitudinal data: What, why, and how? In K. van Montfort, J. H. L. Oud, \& M. C. Voelkle (Eds.), Continuous time modeling in the behavioral and related sciences (pp. 37-54). Springer International Publishing.

Safer, M. A., Levine, L. J., \& Drapalski, A. L. (2016). Distortion in memory for emotions: The contributions of personality and post-event knowledge. Personality and Social Psychology Bulletin, 28(11), 1495-1507. https://doi.org/10.1177/014616702237577

Sarason, I. G., Johnson, J. H., \& Siegel, J. M. (1978). Assessing the impact of life changes: Development of the Life Experiences Survey. Journal of Consulting and Clinical Psychology, 46(5), 932-946. https://doi.org/10.1037/0022-006X.46.5.932 
Scherer, R. F., \& Drumheller, P. M. (1992). Consistency in cognitive appraisal of a stressful event over time. The Journal of Social Psychology, 132(4), 553-555. https://doi.org/10.1080/00224545.1992.9924737

Schmidt, P. J., Grover, G. N., Hoban, M. C., \& Rubinow, D. R. (1990). State-dependent alterations in the perception of life events in menstrual-related mood disorders. The American Journal of Psychiatry, 147(2), 230-234. https://doi.org/10.1176/ajp.147.2.230

Sedikides, C., \& Skowronski, J. J. (2020). In human memory, good can be stronger than bad. Current Directions in Psychological Science, 29(1), 86-91. https://doi.org/10.1177/0963721419896363

Servaty-Seib, H. L. (2014). Using a gain/loss framework to measure impact: The Perceived Impact of Life Event Scale. Journal of Loss and Trauma, 19(4), 331-354. https://doi.org/10.1080/15325024.2013.781468

Sheets, V., Sandler, I., \& West, S. G. (1996). Appraisals of negative events by preadolescent children of divorce. Child Development, 67(5), 2166-2182. https://doi.org/10.2307/1131616

Sheldon, K. M., Boehm, J., \& Lyubomirsky, S. (2013). Variety is the spice of happiness: The Hedonic Adaptation Prevention Model. In I. Boniwell, S. A. David, \& A. Conley Ayers (Eds.), Oxford handbook of happiness (pp. 901-944). Oxford University Press. https://doi.org/10.1093/oxfordhb/9780199557257.013.0067

Sheldon, K. M., \& Lyubomirsky, S. (2012). The challenge of staying happier: Testing the Hedonic Adaptation Prevention model. Personality and Social Psychology Bulletin, 38(5), 670-680. https://doi.org/10.1177/0146167212436400

Shiner, R. L., Allen, T. A., \& Masten, A. S. (2017). Adversity in adolescence predicts personality trait change from childhood to adulthood. Journal of Research in Personality, 67, 171-182. https://doi.org/10.1016/j.jrp.2016.10.002 
Soto, C. J., \& John, O. P. (2017). Short and extra-short forms of the Big Five Inventory-2: The BFI-2-S and BFI-2-XS. Journal of Research in Personality, 68, 69-81. https://doi.org/10.1016/j.jrp.2017.02.004

Specht, J. (2017). Personality development in reaction to major life events. In J. Specht (Ed.), Personality development across the lifespan (pp. 341-356). Academic Press.

Trzesniewski, K. H., Donnellan, M. B., \& Robins, R. W. (2003). Stability of self-esteem across the life span. Journal of Personality and Social Psychology, 84(1), 205-220. https://doi.org/10.1037/0022-3514.84.1.205

Ullman, J. B., \& Bentler, P. M. (2006). Structural equation modeling. In I. B. Weiner (Ed.), Handbook of psychology. Wiley. https://doi.org/10.1002/0471264385.wei0224

Uusberg, A., Taxer, J. L., Yih, J., Uusberg, H., \& Gross, J. J. (2019). Reappraising reappraisal. Emotion Review, 11(4), 267-282. https://doi.org/10.1177/1754073919862617

Vaidya, J. G., Gray, E. K., Haig, J. R., Mroczek, D. K., \& Watson, D. (2008). Differential stability and individual growth trajectories of big five and affective traits during young adulthood. Journal of Personality, 76(2), 267-304. https://doi.org/10.1111/j.14676494.2007.00486.x

van Scheppingen, M. A., Denissen, J. J. A., \& Bleidorn, W. (2018). Stability and change in self-control during the transition to parenthood. European Journal of Personality, 32(6), 690-704. https://doi.org/10.1002/per.2172

Voelkle, M. C., Gische, C., Driver, C., \& Lindenberger, U. (2018). The role of time in the quest for understanding psychological mechanisms. Multivariate Behavioral Research, 53(6), 782-805. https://doi.org/10.1080/00273171.2018.1496813

Voelkle, M. C., \& Oud, J. H. L. (2013). Continuous time modelling with individually varying time intervals for oscillating and non-oscillating processes. The British Journal of 
Mathematical and Statistical Psychology, 66(1), 103-126. https://doi.org/10.1111/j.20448317.2012.02043.x

Voelkle, M. C., \& Oud, J. H. L. (2015). Relating latent change score and continuous time models. Structural Equation Modeling: A Multidisciplinary Journal, 22(3), 366-381. https://doi.org/10.1080/10705511.2014.935918

Voelkle, M. C., Oud, J. H. L., Davidov, E., \& Schmidt, P. (2012). An SEM approach to continuous time modeling of panel data: Relating authoritarianism and anomia. Psychological Methods, 17(2), 176-192. https://doi.org/10.1037/a0027543

Voelkle, M. C., \& Wagner, J. (2017). Analyzing personality change: From average trajectories to within-person dynamics. In J. Specht (Ed.), Personality development across the lifespan (pp. 497-516). Academic Press.

Wagner, J., Lüdtke, O., \& Voelkle, M. C. (2019). Using dynamic panel models to study agerelated differences and time-related changes in personality. European Journal of Personality, 33(3), 420-434. https://doi.org/10.1002/per.2200

Wagner, J., Voelkle, M. C., Hoppmann, C. A., Luszcz, M. A., \& Gerstorf, D. (2018). We are in this together. International Journal of Behavioral Development, 42(1), 34-42. https://doi.org/10.1177/0165025416679742

Walker, W. R., \& Skowronski, J. J. (2009). The fading affect bias: But what the hell is it for? Applied Cognitive Psychology, 23(8), 1122-1136. https://doi.org/10.1002/acp.1614

Watson, D. (2004). Stability versus change, dependability versus error: Issues in the assessment of personality over time. Journal of Research in Personality, 38(4), 319-350. https://doi.org/10.1016/j.jrp.2004.03.001

Watson, D., \& Walker, L. M. (1996). The long-term stability and predictive validity of trait measures of affect. Journal of Personality and Social Psychology, 70(3), 567-577. https://doi.org/10.1037/0022-3514.70.3.567 
Wilson, T. D., \& Gilbert, D. T. (2008). Explaining away: A model of affective adaptation. Perspectives on Psychological Science, 3(5), 370-386. https://doi.org/10.1111/j.17456924.2008.00085.x

Yap, S. C., Anusic, I., \& Lucas, R. E. (2014). Does happiness change? Evidence from longitudinal studies. In K. M. Sheldon \& R. E. Lucas (Eds.), Stability of happiness: Theories and evidence on whether happiness can change (pp. 127-145). Elsevier Science. https://doi.org/10.1016/B978-0-12-411478-4.00007-2 